\title{
EL VINO, COMO RECURSO TURÍSTICO PARA EL FOMENTO DEL DESARROLLO LOCAL. UNA OPORTUNIDAD PARA LAS COMARCAS DEL VINALOPÓ (ALICANTE) Y EL ALTIPLANO YECLA-JUMILLA (MURCIA) ${ }^{1}$
}

\author{
Antonio Martínez Puche \\ Universidad de Alicante \\ Francisco José Morales Yago ** \\ Universidad Nacional de Educación a Distancia
}

\section{RESUMEN}

El cultivo de la vid es una actividad atávica muy relacionada con las comarcas de interior de las provincias de Alicante y Murcia. La presente investigación realiza un análisis comparado entre las comarcas del Vinalopó y el Altiplano murciano, sede de tres rutas del vino certificadas (Alicante, Jumilla y Yecla) por parte de TURESPAÑA. Ello potencialmente tiene la oportunidad de generar una dinamización socioeconómica y una valorización paisajística y patrimonial, basada en el aprovechamiento integral de todos los recursos territoriales y la aplicación de políticas de desarrollo local.

Palabras clave: paisaje; enoturismo; cultura del vino; desarrollo local; diversificación económica; valorización de recursos territoriales.

Recibido: 24 de febrero de 2015

Devuelto para su revisión: 5 de junio de 2015

Aceptado: 24 de septiembre de 2015

Departamento de Geografía Humana. Universidad de Alicante. Apartado 99. 03080 ALICANTE (España).E-mail: antonio.martinez@ua.es

** Facultad de Geografía e Historia. Universidad Nacional de Educación a Distancia. Senda del Rey, 7. 28040 MADRID (España).E-mail: fjmorales@geo.uned.es

1 Proyecto GV/2014/085: «Análisis de la innovación territorial, gobernanza y procesos de resiliencia en la Comunidad Valenciana para el favorecimiento de emprendimientos locales. Identificación de instrumentos, evaluación de indicadores y sistematización de buenas prácticas». Consellería de Educación Cultura y Deporte, Dirección General de Universidades, Estudios Superiores y Ciencia. Generalitat Valenciana. 
The wine, as a tourist resource for the promotion of local development. an opportunity for the region of Vinalopó (Alicante) and the highlands Yecla-Jumilla (Murcia)

\begin{abstract}
The work of the vine is old with the districts of interior of Alicante and Murcia. This investigation make an analysis compared between the Municipalities of Vinalopó and municipalities of Murcia (Alicante, Jumilla and Yecla). Routes of the Certified Wine for TURESPAÑA. It potentially has the opportunity to generate a socioeconomic growth and a valuation of the landscape and patrimonial, based on the integral use of all the territorial resources and the application of political of local development
\end{abstract}

Keyword: landscape; territory; culture of the wine; tourism of the wine; Local Development; economic growth and economic diversification.

\title{
1. INTRODUCCIÓN
}

La cultura del vino está viviendo un momento de gran interés comercial en algunas zonas del Estado español, gracias a su popularización en los mercados, a la aceptación turística y social, y a procesos de innovación empresarial, que han mejorado la calidad de los caldos y la promoción de bodegas. Además, se ha superado la dualidad entre agricultor (materia prima) y el productor (el que realizaba la vinificación y elaboración del vino), convirtiéndose además en una actividad terciara en la que la práctica turística, enriquece y fortalece el aprovechamiento de recursos del territorio (patrimonio cultural y medio ambiental, infraestructuras y equipamientos turísticos, economía local), así como la valorización, conocimiento y preservación de aspectos ligados a la cultura del vino (historia, tradición, paisajes de vid, bodegas, aperos de labranza, características y tipologías edáficas, variedad de uvas, producción vinícola, catas de sabores, etc.).

En la actualidad, en un mundo globalizado, los turistas, cada vez más experimentados, presentan nuevas exigencias y motivaciones, reclamando la máxima calidad posible, un respeto medioambiental y un trato cada vez más personalizado. Ante esta situación, los destinos turísticos, unos para evitar su estancamiento y declive y otros para impulsar su desarrollo, están reinventando su oferta de productos y servicios turísticos, siendo la búsqueda de nuevos productos una de las estrategias más comunes. También en territorios de interior como el que no ocupa, que no tienen una tradición turística sino industrial (sistemas productivos locales ligados al mueble, tapizados, calzado y piedra natural), pero que sin embargo, aprovechándose de una tradición agrícola y vinatera, están valiéndose de programas que han incentivado la producción de vino y el fomento del enoturismo (PDR-Murcia, Ruralter, PDPT, etc.). Con la burbuja inmobiliaria los espacios de interior se han visto amenazados por la construcción residencial. Los paisajes de la vid reafirman y confieren aspectos singulares que traspasan el paso del tiempo, dotando a estos espacios de unas señas de identidad muy arraigadas, cuestión que no cabe duda, son el fiel testigo del paso del tiempo y por ello de un atractivo identitario para los propios habitantes de la zona como para los potenciales visitantes. 
En este trabajo se presenta de qué forma el turismo enológico y las rutas del vino, puede suponer un producto de gran potencial turístico y cultural, tanto desde el punto de vista de la demanda como de la oferta (patrimonio, gastronomía, turismo activo, etc.). También la importancia e implicación de los agentes locales (capital social), que se implementan a nuevas inversiones exógenas (productores y bodegas), que están intentando establecer procesos de endogeneización, cultivando variedades de uva autóctonas y valorizando paisajes y paisanajes a través de las señas de identidad, creando puestos de trabajo y promocionando el territorio (place branding).

En este sentido planteamos en el presente artículo, tres aspectos:

1. La tradición vitivinícola en las comarcas del Vinalopó (Alicante) y Altiplano (Murcia). Un paisaje heredado, y una tradición productiva, que merece la pena conservar. Contexto histórico y territorial.

2. Sostenibilidad integrada en la gestión de los recursos del territorio estableciendo un equilibrio entre la economía, la ecología y la etnografía a través de la enología. Recuperación de las actividades agrícolas y posibilidad de diversificación económica, optimizando los recursos locales (ambientales y culturales). Todo ello sin olvidar la implicación de los aspectos sociodemográficos y del capital social, en la que agentes públicos y privados, pueden dar lugar a equipamientos e infraestructuras en el marco de habilitar nuevos yacimientos de empleo basados en la agricultura, la gestión de museos, la comercialización de vinos en las bodegas, profesionales para las visitas guiadas, itinerarios culturales. Se identificaran programas y proyectos que han ayudado a ello. También se analizarán la compatibilidad de usos del suelo.

3. Rutas del vino en Alicante y Murcia. Definición de la oferta y motivación de la demanda (rutas del vino, propiamente dichas en el marco de la definición de TURESPAÑA) y sus repercusiones territoriales (Place branding).

El enoturismo implica un disfrute de los productos locales y se instaura en el cada vez más generalizado turismo experiencial. Paisajes, entornos, construcciones arquitectónicas (tradicionales o más vanguardistas), gastronomía local, son recursos que juegan un papel fundamental en la apreciación de los turistas. Y además, forman parte del conjunto de atributos que modelan las atracciones turísticas de los destinos, sirviendo, a su vez como reclamo promocional para futuras repeticiones o para atraer nuevos clientes, por lo que se convierten en un interesante instrumento de mercadotecnia (Boniface, 2003; Long, 2004; Richard, 2002: Warde, 1997).

En el año 2001 la Secretaría General de Turismo, en colaboración con ACEVIN (Asociación de Ciudades del Vino), realizó un primer estudio para definir el producto «Rutas del Vino de España» y sus normas de autorregulación. Finalmente, se pusieron en marcha durante el periodo 2002-2003, agrupando las Denominaciones de Origen de Jumilla, La Mancha, Montilla-Moriles, Penedés, Rías Baixas y Utiel-Requena (Jover, 2009). Junto a ACEVIN y la Secretaría de Estado de Turismo, a través de Turespaña, también impulsó esta iniciativa el Ministerio de Medio Ambiente y Medio Rural y Marino. En 2003 el Ministerio de Industria, Comercio y Turismo revindicaba las Rutas del Vino de España (RVE) como productos turísticos innovadores, si bien ACEVIN, ya estaba trabajando en 
la promoción de los caldos patrios desde su creación en 1994. Estas rutas integran los recursos y servicios turísticos de interés de una zona vitivinícola, con el fin de construir un producto a partir de la calidad e identidad del destino, optimizando la comercialización conjunta, el nivel de satisfacción de la demanda y el desarrollo socioeconómico de los territorios. Tales planteamientos siguieron teniendo vigencia y continuidad en las conclusiones del Plan de Turismo Español 2020, presentadas en 2007, en las que las rutas del vino aparecían como producto innovador asentado en la creación de experiencias y vivencias para un turista cada vez más dinámico, que busca productos turísticos de alto valor añadido. En este sentido cabe señalar que el Plan Nacional e Integral de Turismo 20122015, también ha apostado por generar una diferenciación relevante para el consumidor, en la que todos los recursos culturales, naturales, empresariales y de servicio público, se ponen al servicio del turista (PINT 2012-2015).

Todo ello a pesar de que la viticultura en algunos territorios como la Comunidad Valenciana y Murcia, ha experimentado un retroceso notable en sus explotaciones según el censo agrario en una década (cuadro 1). Por ello consideramos de gran importancia acciones vinculadas al enoturismo, al objeto de mantener las explotaciones, y reforzarlas con una funcionalidad no sólo productiva y vinícola; también como preservación del medio natural y la función turística.

\section{Cuadro 1 \\ EXPLOTACIONES VITIVINÍCOLAS \\ EN LA COMUNIDAD VALENCIANA LA REGIÓN DE MURCIA. 1999 Y 2009}

\begin{tabular}{|l|r|r|r|r|}
\hline & Explotaciones & Ha & Explotaciones & \multicolumn{1}{c|}{ Ha } \\
\hline Comunidad Valenciana & 23.300 & 80.138 & 10.916 & 62.665 \\
\hline Alicante & 7.896 & 22.027 & 3.121 & 15.486 \\
\hline Murcia & 5.931 & 40.714 & 3.382 & 33.045 \\
\hline
\end{tabular}

Fuente: INE, Censo Agrarios 1999 y 2009.

El turismo gastronómico ya atrajo a seis millones de visitantes en 2011, cuyo gasto medio creció un 7\%, en contraposición con la subida del 1\% del turista general, siendo una de la ventajas competitivas de este segmento turístico la desestacionalización del sector, y la posibilidad de captar nuevos mercados. Así, dentro del turismo gastronómico, aparece el enoturismo como una de las opciones más en boga (Martínez y Jover, 2012). Ello se pone de manifiesto en el informe que se presentó durante 2013 en las rutas del Vino de España por parte de Acevín. En efecto, la consolidación del turismo enológico arrojaba un incremento en 258.617 visitas en términos absolutos, lo que suponía un aumento del 18'08\% respecto a 2012. Si bien hay que considerar que el número de bodegas sobre las que se han recogido las muestras para la realización del informe aumentó, por la incorporación de nuevas rutas, el dato es especialmente positivo puesto que el incremento porcentual de las visitas fue superior al de bodegas participantes en el estudio (figura 1). 
En el contexto actual el turismo enológico se consolida en España como complemento al turismo de sol y playa y como uno de los motores del turismo rural y de interior, según los datos recogidos en el Informe del Observatorio de las Rutas del Vino en 2012 y que presentó ACEVIN. En efecto, la Asociación Española de Ciudades del Vino, contaron con un total de 1.430 .592 visitantes. En el informe se plasma una pérdida de 97.703 visitantes respecto a 2011, año en el que se alcanzó la cifra de 1.528.295 visitantes, considerando los datos de 546 bodegas de 22 Rutas del Vino. Sin embargo, se tiene que matizar esa cifra porque el número de bodegas incluidas es mucho menor en el informe de 2012, conta-

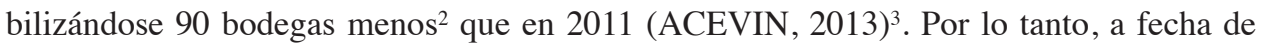
2015, existen 21 rutas de Vino certificadas por TURESPAÑA, entre las que se encuentran los tres objetivos de estudio (Yecla, Jumilla y Alicante).

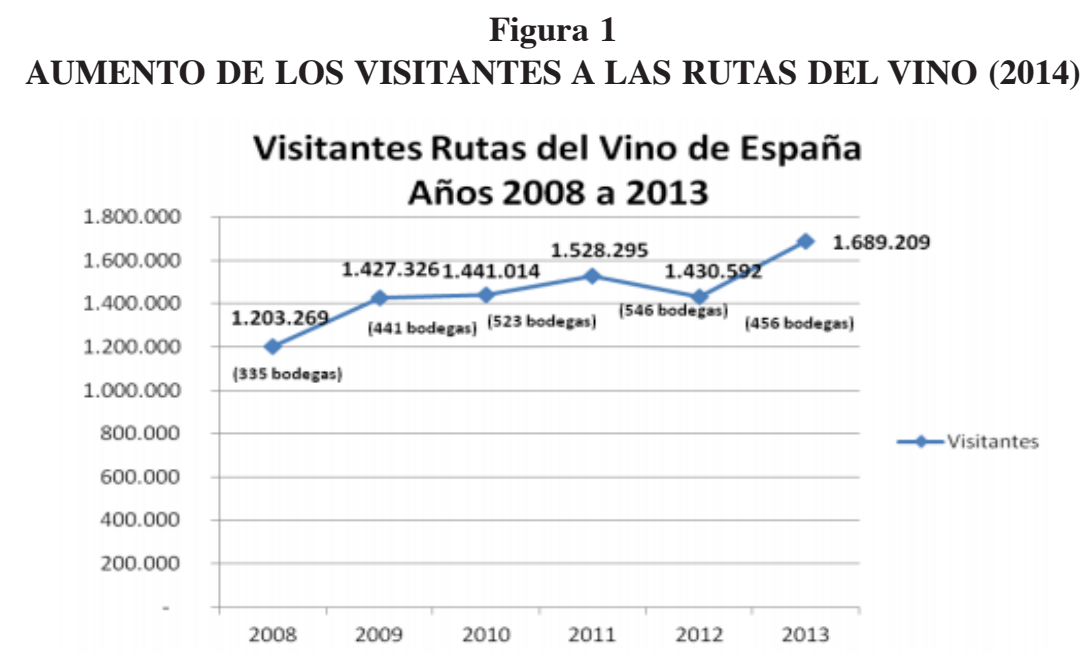

Fuente: ACEVIN, 2014.

Por último, se combina la búsqueda documental con trabajo de campo que ha consistido en examinar el espacio objeto de estudio (entrevistas personales ver -Anexo 1-), ayudaron a realizar una análisis DAFO. Así, se analizó la evolución del número de empresas vinculadas a la ruta del vino e información como han sido la utilización del Catastro de rústica y diversos datos proporcionados a través del INE, ACEVIN, TURESPAÑA y anuarios estadísticos editados por las comunidades autónomas de Valencia y Murcia así como a nivel estatal.

2 De hecho, si se tomaran en cuenta los datos de las cuatro rutas excluidas en 2012 (las de Rioja Alta y Tenerife, que no aportaron datos, y las de Alicante y Condado de Huelva, que no se incluyeron porque no están certificadas todavía) el número total de visitantes se mantendría estable o incluso aumentaría. Por ello, no se puede hablar de un retroceso en el enoturismo, más bien lo que se está produciendo es su consolidación como una actividad complementaria al potencial turístico español y una interesante alternativa en un momento en el que se tiende a reducir la distancia del recorrido y la duración de las vacaciones.

3 Origen. La revista del Sabor Rural, http://www.origenonline.es/noticias-rutas-del-vino-espana y http:// www.wineroutesofspain.com/ver/ 


\section{EL DESARROLLO DE LA VITICULTURA Y ACTIVIDAD ENOTURÍSTICA EN LA DENOMINACIÓN DE ORIGEN ALICANTE}

Alicante, provincia caracterizada por el modelo turístico de «sol y playa», ha descuidado hasta ahora las potencialidades de desarrollar el turismo enológico en sus comarcas interiores. Si bien, desde hace tiempo ha existido un notable interés de los excursionistas por adquirir directamente de las pequeñas bodegas el apreciado y afamado «Fondillón», exclusivo de la D.O. Alicante (figura 2). Algunos ilustres intelectuales de estas tierras como Cavanilles o Azorín han glosado las virtudes de los vinos alicantinos:

El verdadero Alicante debe hacerse de uvas Monastrell, y de aquellas resulta aquel vino, espeso, de un sabor dulce, con alguna aspereza, tan estimada en todas las naciones (Cavanilles).

Vino centenario, su sabor es dulce, sin empalago; por su densidad empaña el cristal; huele a vieja caoba (Azorín).

Esta Denominación de Origen fue una de las pioneras. Reconocida como tal en 1932, en la actualidad agrupa alrededor de 50 bodegas, más de 2.500 viticultores y cuenta con una extensión superior a las 14.600 Hectáreas de viñedos. La situación respecto a la utilización del vino como elemento turístico cambia cuando en el sector bodeguero tradicional se despierta la curiosidad por el enoturismo, se empiezan a hacer las primeras inversiones con esa orientación en establecimientos hosteleros y los municipios vitivinícolas confirman la necesidad de establecer a nivel comarcal estrategias promocionales.

\subsection{Alicante una provincia con tradición vitivinícola reconocida}

El vestigio más antiguo sobre la práctica enológica en la Península Ibérica corresponde al poblado ibero de Benimaquia (Denia). Allí los arqueólogos Gómez y Guerin han identificado los restos de un lagar que atestigua el proceso de vinificación en el siglo VI a.C. (Piqueras, 2009). La romanización de nuestras tierras a partir del siglo II a.C. consolidó el cultivo de la vid y la elaboración de vinos para su exportación como se desprende de los talleres de ánforas vinarias descubiertos en la playa de la Almadraba (Denia) y de El Campello. Las grandes ciudades, como Elche, se abastecen tanto de estos vinos locales como de otros importados desde las costas de Tarragona, como ha demostrado Juan C. Márquez en su estudio sobre El comercio romano en el Portus Illicitanus (1999).

Mucho se ha escrito sobre la gran importancia que el vino de Alicante alcanzó en el mercado internacional durante la Edad Moderna. De él se sabe que a mediados del siglo XVII era el más caro de Inglaterra (Unwin, 1991) y que hasta finales del siglo XVIII fue el único vino español de renombre en Alemania, donde en 1616 era, junto al Malvasier y el Peter Siemens, uno de los tres vinos dulces más cotizados, que en razón de su alta estima, según Basserman-Jordan (1923), había que beber en copas de plata y no en copas de cristal como los vinos del Rin y del Mosela. En el siglo XIX, encontramos referencias narrativas salidas de la pluma de Emilio Salgari o de Alejandro 
Dumas, el cual cita en su obra El Conde de Montecristo (1844-1846) al vino de Alacant (Fondillón) en un párrafo del capítulo cuarto. Dirigiéndose al Mayor Cavalcanti, el conde le pregunta:

«¿Queréis tomar alguna cosa? ¿Un vaso de Jerez, de Oporto, de Alacant? De Alacant, puesto que tanto insistís, es mi vino predilecto» ${ }^{4}$

En la segunda mitad del siglo XIX, la vid fue uno de los cultivos que experimenta mayor desarrollo en el País Valenciano; su expansión se realiza a partir de 1878, cuando la filoxera arruinó gran parte de las vides francesas. El tratado firmado con el país vecino benefició la expansión de la vid en detrimento del cereal. El gran impulso que durante estos años tuvo el negocio del vino en las comarcas del Vinalopó, estuvo secundado por los negociantes locales que crearon grandes establecimientos, así como por los propietarios y cosecheros que «emplearon hasta el último céntimo de sus utilidades en hacer nuevas plantaciones de viñas, reformar las antiguas, mejorar el cultivo y edificar bodegas para elaborar sus productos con mayor esmero y con arreglo a lo que la ciencia y la práctica nos enseña, que ha hecho de nuestra ciudad-Villena- un centro comercial de verdadera importancia, a donde además de los comerciantes del país, acuden extranjeros, atraídos por la pureza y calidad de los vinos... y buena fe en los negocios que disfrutamos» (Martínez, 1999). En el caso de la capital del Alto Vinalopó (Villena), hay que mencionar al productor Cristóbal Amorós, que se convirtió en uno de los principales exportadores de vino de la provincia de Alicante, teniendo sus vinos un reconocido prestigio en todo el mundo, habiendo sido premiados «en muchísimas exposiciones, entre ellas, las de Barcelona de 1888, Amberes, Chicago, El Cairo, Suez, París y otras muchas» ${ }^{5}$.

En marzo de 1891 la Estación Enológica de España en París, publicó la lista oficial y completa de producción de vinos en España durante el año anterior, situándose la provincia de Alicante como mayor productora a nivel nacional con una producción de 3.466.846 $\mathrm{Hl}$ de vino, por encima de provincias como Valencia con 2.166.000 Hl, Barcelona con 2.800.744 Hl y Ciudad Real con 2.300.000 Hl (Martínez, 1999).

Ya en épocas más recientes y con la llegada de la plaga de la filoxera en 1907 a los viñedos alicantinos, nuestra provincia nunca volvió a vivir un apogeo comercial y productivo como el vivido en los periodos referenciados. La demanda cayó, dado que fuimos uno de los últimos territorios en ser infectados y cuando replantamos con pies americanos, resistentes a la plaga, nuestros clientes ya tenían otros suministradores (Piqueras, 2009).

4 También descubrimos, líneas más tarde, la costumbre impuesta por Luis XIV de Francia (1638-1715), de degustar el vino con bizcochos: «El conde llenó un vaso y vertió en el segundo algunas gotas del rubí líquido que contenía la botella cubierta de telas de araña y de todas las señales que indican lo que añejo del vino. El mayor tomó el vaso lleno y un bizcocho. El conde mandó a Bautista que colocase la botella junto a su huésped, que comenzó por gustar el Alacant con el extremo de sus labios, hizo un gesto de aprobación, e introdujo delicadamente el bizcocho en el vaso». El Conde de Montecristo, ed. Círculo de Lectores. Madrid, 1983, p. 721.

5 Periódico, Villena Joven, n ${ }^{\circ}$, Villena 14 de junio de 1914. 


\subsection{La Ruta del Vino de Alicante. Creación y objetivos}

La creación de la Ruta del Vino de la Denominación de Origen Alicante se llevó a cabo durante los primeros meses de $2008^{6}$.

En ella participaron algunos municipios del Alto y Medio Vinalopó liderados por Pinoso. Lo que surgió con vocación local, se ha ido convirtiendo en un propósito de alcance intercomarcal y provincial. El 17 de enero del mismo año este municipio alicantino acogió la presentación oficial de la cuarta fase de la auditoría de las Rutas del Vino de España que agrupaba a 19 rutas. La prensa provincial explicaba así la situación del caso alicantino:

La Ruta del Vino de Alicante es todavía un proyecto, ya que antes deberá ser certificada y amparada por el Ministerio de Agricultura y el de Industria y Turismo, según explica Francisco Amorós [presidente del Consejo Regulador D.O. Alicante]. A los cuatro pueblos alicantinos citados [Algueña, Pinoso, Monóvar y Villena], con enorme tradición vitivinícola, podrían sumarse en breves días otros muchos (...). De salir adelante el proyecto, el Ministerio de Industria tendrá que certificar a las empresas y bodegueros participantes con el sello genérico de Rutas del Vino de España, que ya ha pasado a integrarse en la oferta turística de Turespaña ${ }^{7}$.

En octubre de 2009 la Diputación provincial firmó un convenio con las siete poblaciones $^{8}$ que conformaron inicialmente la Asociación de Municipios para el Fomento de las Rutas del Vino de Alicante. El fin último de esta suma de esfuerzos era ofrecer un atractivo más que diversificara el producto turístico de la Costa Blanca9.

La creación de las rutas turísticas enológicas favorece la cooperación y relación entre las diferentes empresas de las áreas rurales e impulsa tanto el desarrollo socioeconómico integral como sostenible del territorio. Las mismas fuentes [Diputación Provincial] afirmaron que ese itinerario se convierte en un destino turístico de calidad, al tiempo que contribuye tanto a generar empleo y riqueza como a mejorar la calidad de vida de la población local ${ }^{10}$.

La Asociación Ruta del Vino de Alicante, constituida como ente gestor en noviembre de 2009 por los siete municipios del Vinalopó, el Consejo Regulador D.O. Alicante y el

6 El proyecto se remonta a un estudio prospectivo encargado previamente por el ayuntamiento de Pinoso en 2006 a partir del que se consideró la conveniencia de apostar por un modelo de desarrollo turístico bajo las directrices del modelo 1: Gastronomía, enología y sistema productivo tradicional. (Jover, 2009: 116).

7 LA VERDAD, Alicante, 03-02-2008.

8 Algueña, Hondón de los Frailes, Monóvar, Novelda, Petrer, Pinoso y Villena.

9 «La iniciativa propuesta por el municipio de Pinoso y en la que participan también las localidades de Monóvar, La Algueña, Villena, Petrer, Hondón de los Frailes, La Romana y Novelda, tiene como objetivo el impulso turístico de las comarcas a las que pertenecen esas poblaciones (...) La cuenca del Vinalopó cultiva especialmente cepas de la variedad monastrell, con las que se obtienen unos vinos tintos frutales con graduaciones comprendidas entre los 12 y 16 grados». En LAS PROVINCIAS, Valencia, 09-09-2009.

10 Las Provincias, 09-09-2009. 


\section{Figura 2 \\ DISTRIBUCIÓN DE LAS COMARCAS \\ ENOLÓGICAS DE LA PROVINCIA DE ALICANTE}

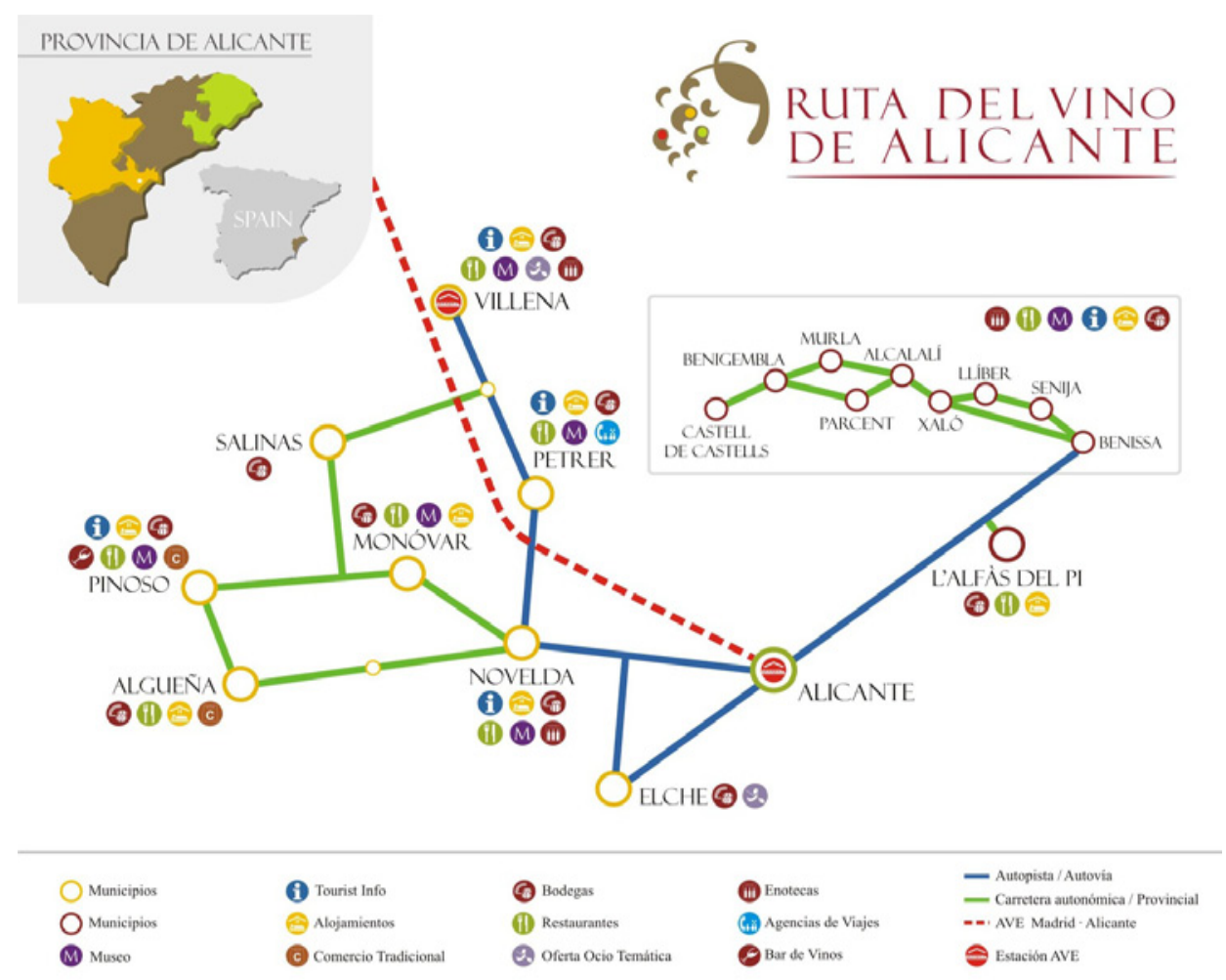

Fuente: Asociación Ruta del Vino de Alicante.

Patronato Costa Blanca en representación de la Diputación Provincial de Alicante, acudió por primera vez a la Feria Internacional de Turismo (FITUR) en el año 2010, donde promocionó sus vinos con diferentes animaciones, catas y degustaciones.

A lo largo del año 2010 se fueron incorporando más poblaciones alicantinas a la Asociación de la Ruta del Vino de Alicante (figura 2), como Alfaz del Pi, la Mancomunidad de la Vall del Pop, en la Marina Alta, y el municipio de Salinas, en la Comarca del Alto Vinalopó. Este proyecto de turismo enológico, que se constituyó gracias a la iniciativa de la edil de Turismo de Pinoso, María José Jover, está siendo en la actualidad tutelado por el Patronato Costa Blanca, que ha visto la oportunidad de justificar acciones relativas a la proyección y divulgación de productos turísticos complementarios al sol y playa ${ }^{11}$. De hecho, las acciones que este organismo está llevando a cabo siempre tienen un marcado

11 Actualmente la Diputación de Alicante ha puesto en marcha un Plan Estratégico Provincial en el que se hace mención a distintas variables turísticas y el enoturismo está incluido. 
carácter promocional: creación de una página web, edición de materiales publicitarios y realización de eventos enológicos bajo el nombre de «La Calle de Baco» en el Museo Arqueológico Provincial de Alicante (MARQ).

Todas estas acciones de comunicación y relaciones públicas están bien, pero no son suficientes. Como aludimos en el apartado anterior, para consolidar un producto turístico integrado se debe tener en cuenta no sólo la estética coyuntural del concepto «cultura del vino», sino las raíces atávicas, histórico-culturales, patrimoniales, paisajísticas y socioeconómicas que el vino ha establecido durante siglos en las tierras de la provincia de Alicante (Martínez, 1999). A su vez, habría que prestar atención a la importancia que tuvo en el pasado la elaboración del vino en algunas poblaciones, así como las posibilidades presentes y futuras de complementar recursos turísticos desde una visión estructural e integrada ligados no solamente a las infraestructuras (alojamientos), sino también a la gastronomía, el patrimonio histórico-cultural y arquitectónico y las actividades al aire libre (senderismo, turismo activo, etc.).

La Ruta del Vino de la Provincia de Alicante (figura 3) se puede convertir en un verdadero complemento de rentas para los municipios, aprovechando que el vino español está viviendo un momento de consolidación comercial internacional desde hace unos años ${ }^{12}$. Eso sin olvidar su aportación como ingrediente básico de una más que saludable dieta mediterránea y su utilización como elemento terapéutico de baños, tratamientos y masajes que persiguen el bienestar de las personas. Por otra parte, observamos que progresivamente se ha superado la dualidad entre agricultor (materia prima) y viticultor-bodeguero (producto) a causa, por ejemplo, de la proliferación de cooperativas que recogen las uvas, elaboran sus vinos y los venden. Eso permite aunar la actividad productiva y la turística, aunque en los territorios de la provincia de Alicante el enoturismo no es una actividad consolidada en general, a excepción de algunas decididas empresas particulares.

Los miembros de la Asociación Ruta del Vino de Alicante establecen estos objetivos y estrategias a corto y medio plazo (Martínez y Jover, 2012):

- Ser la principal referencia Enoturística de la Comunidad Valenciana con marca asociada a «Rutas del Vino de España» y como un valor de calidad.

- Seguir fomentando las sinergias con las instituciones, entidades y agentes relacionados directa o indirectamente con el turismo y el mundo vitivinícola.

- Conseguir financiación para la estabilidad de la Ruta y el desarrollo y puesta en marcha del Plan de Señalización y Formación.

- Establecer estrategias que contribuyan a distribuir los flujos turísticos por toda la provincia y a mejorar el sistema de acogida.

12 Según datos de la Organización Internacional de la Viña y el Vino (OIV), creada en 2001, los vinos de España en 2011, se situaban a la cabeza de Europa en superficie plantada de viñedo, suponiendo esta un $30 \%$ de la superficie total europea y cerca de un $14 \%$ de la superficie mundial (ICEX, 2011. El vino en cifras. Informe elaborado por el Observatorio Español del Mercado del Vino, p.4). En 2012 el 11\% del viñedo del Estado Español correspondió al viñedo de la Comunidad Autónoma del País Valenciano, siendo la segunda comunidad autónoma en superficie dedicada tras Castilla-La Mancha y tras superar a Extremadura con relación a la superficie dedicada en 2011 (ICEX, 2011, op. cit.) 
- Disponer de un observatorio provincial que permita conocer la evolución de la oferta y de la demanda.

- Continuar trabajando en la implantación del Manual de Producto de la RVE y la mejora continua del modelo enoturístico en todas las empresas y municipios.

\section{Figura 3 \\ ENTRAMADO PÚBLICO-PRIVADO \\ DE LAS RELACIONES DE LA RUTA DEL VINO DE ALICANTE}

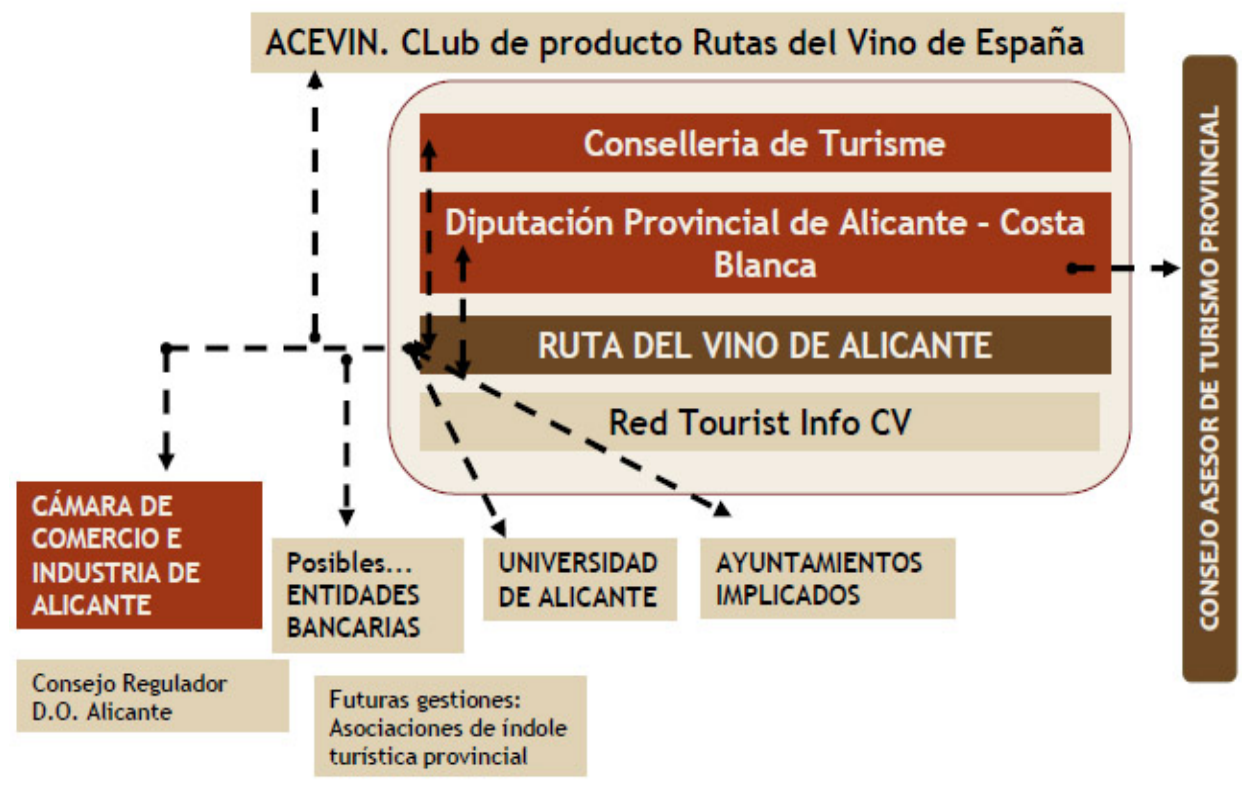

Fuente: Asociación Ruta del Vino de Alicante. 2013.

\subsection{Gestión de recursos y creación de productos en Pinoso y Villena}

En la provincia de Alicante, 25 de las 36 bodegas certificadas en 2012 por la Denominación de Origen Alicante, pertenecen a las comarcas del Alto y Medio Vinalopó, embrión de la actual ruta del Vino de Alicante. De hecho, de este $70 \%$ de bodegas, un total de 11 se encuentran en los municipios de Villena (6) y Pinoso (5).

El municipio de Pinoso emprendió la actividad turística apostando por un modelo de desarrollo basado, especialmente, en el turismo del vino y gastronómico a partir de 2006. Ello se debe al importante peso que, tradicionalmente, ha tenido la viticultura en este municipio y que, por tanto hace que en la actualidad, todos los elementos que rodean a esta actividad tengan una significativa implicación, directa o indirecta, en las rentas de una gran parte de la población. Por este motivo, se considera fundamental conservar, mantener y reforzar dicha actividad, a la vez que reconocer el trabajo realizado por sus antepasados. 
Cuadro 2

EMPRESAS VINCULADAS A LA RUTA DEL VINO

\begin{tabular}{|l|r|r|r|r|}
\hline & \multicolumn{2}{|c|}{ PINOSO } & \multicolumn{2}{c|}{ VILLENA $^{13}$} \\
\hline Tipo de establecimiento & Número & \multicolumn{1}{|c|}{ Plazas } & \multicolumn{1}{c|}{ Número } & \multicolumn{1}{c|}{ Plazas } \\
\hline Restaurantes & 13 & 1.1185 & 10 & 1.000 \\
\hline Bodegas & 5 & & 5 & \\
\hline Enotecas & 1 & & 2 & \\
\hline Empresas servicios Turísticos & -- & & 2 & 65 \\
\hline Hoteles & -- & & 1 & 12 \\
\hline Hostales & 1 & & -- & 22 \\
\hline Casas Rurales & 2 & 18 & 3 & -- \\
\hline Albergues & 1 & 70 & & \\
\hline
\end{tabular}

Fuente: http://www.turismovillena.com/ y Andreu R. y Verdú L., (2012).

De esta forma, según afirma la corporación municipal, se pretende «posicionar los vinos que ofrecen las viñas de este pueblo en el lugar que merecen». Dentro de la apuesta por este tipo de turismo tematizado, la Concejalía de Turismo de Pinoso perseguía crear un producto turístico a través del cual poder promocionar los vinos locales, junto con su gastronomía y su oferta complementaria. Para ello, se piensa en la creación de una ruta turística de ámbito local, que posteriormente se transformaría en un proyecto de ámbito provincial. Igualmente, con su creación se busca aprovechar las oportunidades que ofrece este tipo de turismo, el cual se encuentra en una situación emergente, pero siempre creando un producto diferenciador, competitivo y de calidad.

Por otra parte, Villena, en el marco del Plan de Dinamización de Producto Turístico (2007-2010), muy enmarcado en el turismo patrimonial y activo, planteaba la posibilidad de aprovechar también su tradición vitivinícola y su diversidad gastronómica. Aprovechando los medios técnicos y los incentivos del PDPT, comienzan a implicar a establecimientos de restauración, alojamiento y empresas de servicios, creando hasta un rincón del Vino, como oficina de información turística y de comercialización de productos locales, entre ellos, vino de las diferentes bodegas localizadas en el término municipal. También algunas empresas bodegueras, comienzan a plantear proyectos de enoturismo propios. Destaca el proyecto de la bodega Francisco Gómez o Sierra de Salinas (de capital yeclano), que ofrecen catas y visitas guiadas a sus visitantes. Pero no existe una coordinación entre los diferentes establecimientos, ni hay una estrecha colaboración entre la concejalía de turismo y las bodegas del Municipio, a pesar de los intentos de establecer una ruta coherente y con una oferta temática integrada, por parte de esta última (catas, visitas culturales, actividades de turismo activo, etc.).

En los municipios de la provincia de Alicante el enoturismo no es una actividad consolidada en general, y participa de notables limitaciones. En la actualidad se ha identificado una ausencia de líderes que encarrilen el proyecto (esperemos que desde la gerencia habilitada desde el mes de mayo de 2014, se consiga ese liderazgo), y una política turística que

13 Aquellos que en la página web municipal, aparecen como miembros de la ruta del Vino de Alicante. 
prima al sol y playa, frente a otras iniciativas de interior que además están bajo la marca multiproducto «Costa Blanca». La ausencia de una cultura turística en los municipios de interior, tampoco ayuda a establecer estrategias mancomunadas en las que posicionar el recurso enogastronómico. Hace falta dotar de contenido y singularidad a la ruta del vino de Alicante, aprovechando los recursos y equipamientos turísticos ya existentes, reforzando otros, fomentando iniciativas intermunicipales, aprovechando el ocio de proximidad, y articulando políticas locales y supralocales que favorezcan un producto real, y una verdadera oportunidad turística para los «municipios del vino» de la provincia.

El 13 de mayo de 2014, se aprobó en la XX Asamblea de ACEVIN, celebrada en Jerez de la Frontera, la certificación de las rutas del Vino de Alicante y Campo de Cariñena. Eso ha resultado un gran éxito para los municipios y las empresas de producción y servicios, vinculados al vino y a la restauración de Algueña, L'Alfas del Pi, Monovar, Novelda, Petrer, Pinoso, Salinas, Villena y la Mancomunidad de la Vall del Pop. La última estadística del Observatorio Turístico Nacional, sobre enoturismo en España, en 2013, cifraba en 1.430 .592 el número de visitantes a bodegas, un aumento del 16'4\% respecto al año anterior. En el caso concreto de la provincia de Alicante según datos publicados por la Denominación de Origen Vinos de Alicante, el interés por la viticultura atrajo en 2013 a 31.000 personas. Sin ir más lejos, la bodega Francisco Gómez, en el término municipal de Villena, recibía en el año 2009 a 2.000 visitantes y en 2014 recibió a 6.300 visitantes ${ }^{14}$. En este sentido, no es de extrañar que hayan bodegas en Alicante que nacen enfocadas hacia el enoturismo. De hecho la venta en bodegas alcanzó en 2014 porcentajes que superaron el $20 \%$ de las ventas totales, según la gerente de la ruta del vino de Alicante.

Figura 4

SEÑALÉTICA ACTUAL

DE LA RUTA DEL VINO

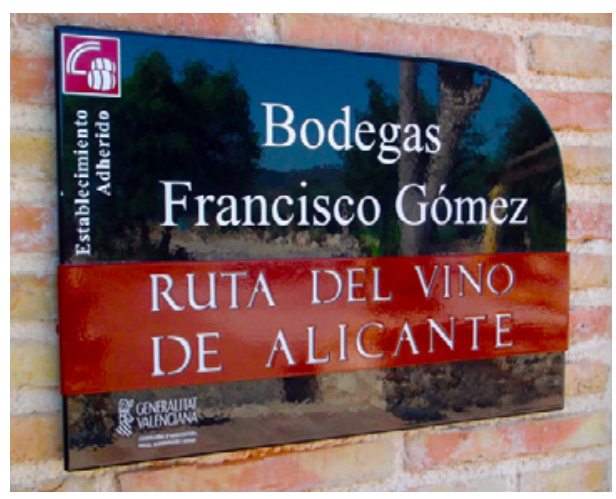

Fuente: Bodega Francisco Gómez.

\section{Figura 5 \\ PROMOCIÓN \\ VINOS DE PINOSO}

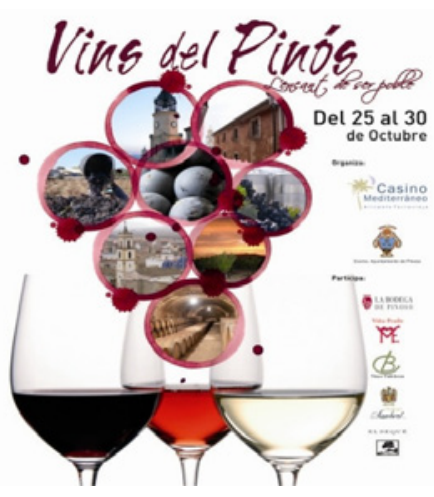

Fuente: Ayuntamiento de Pinoso.

14 Entrevista-cuestionario a la bodega Francisco Gómez, que se ha pasado a un número de empresas de las tres rutas del Vino analizadas, y cuyo modelo se inserta como anexo. En este sentido cabe señalar, que todos los entrevistados, valoraban que la Ruta del Vino de Alicante, estaba en un nivel «aceptable», que es el $3^{\circ}$ de los cinco niveles especificados en la encuesta-entrevista. 


\section{EL DESARROLLO DE LA VITICULTURA Y ACTIVIDAD ENOTURÍSTICA EN LA DENOMINACIÓN DE ORIGEN JUMILLA}

\subsection{Jumilla, una agrociudad vitivinícola por excelencia}

Existen vestigios del cultivo de la vid en Jumilla ${ }^{15}$ desde la época de la romanización hispánica, aunque las primeras noticias que se refieren en concreto a este cultivo datan del siglo XVI, en los que los acuerdos del Consejo de Jumilla hacen mención a una pequeña área de viñas de regadío que se extendía en la periferia de la entonces villa, pero que era insuficiente para el consumo local. Durante el siglo XVII el cultivo de la vid fue aumentado progresivamente puesto que en la Actas Capitulares del Archivo de la Catedral de Murcia de 1667 aparece por primera vez consignado el pago por parte de Jumilla de un diezmo por las rentas debidas a la producción de vino (Morales, A. 1972). En el Catastro del Marqués de la Ensenada figuran un total de $335 \mathrm{Ha}$. cultivadas de las cuales 166 Ha. correspondían a regadío y el resto $169 \mathrm{Ha}$. a secano, estas vides se localizaban en la proximidad del núcleo urbano en los paraje del «El Prado» y «Los Viñazos».

Para mediados del siglo XIX, se hace un cálculo aproximado de $500 \mathrm{Ha}$. de viñedo, lo que significa una superficie reducida y poco significativa en relación a otros cultivos, esencialmente los cereales de secano (Morales, 1972). El último tercio de este siglo cuando la plaga de filoxera castigaba a varios países europeos, esencialmente a Francia se propició un espectacular desarrollo de la vid, de hecho afirma Madoz que: «se produce vino como unas 15000 arrobas de excelente calidad y de un aroma muy superior, especialmente el que se recoge en el partido de la Cueva Negra y Casa del Rico». A partir de 1950 se inició un nuevo periodo de desarrollo vitivinícola que condujo a la creación de la denominación de origen Jumilla en 1961, lo que supuso un importante reconocimiento por ser una de las primeras de España. Actualmente la industria vitivinícola de Jumilla es la principal actividad económica de la ciudad, la mayor generadora de empleo y proyección internacional de la misma así como un destacado referente turístico que permanece asociado a un rico patrimonio cultural y paisajístico.

Por su enclave geográfico al tratarse de un espacio de transición entre la meseta y el litoral mediterráneo, los viñedos aparecen en amplios valles y piedemontes como lugares propicios por la climatología y calidad de los suelos para el cultivo de la vid que nunca supera los 800 metros de altitud. La denominación de origen abarca el municipio de Jumilla con más de 19.000 Ha. de cultivo y una serie de municipios de la Comunidad de Castilla-La Mancha como son: Montealegre del Castillo, Fuente Álamo, Ontur, Hellín y Albatana todos ellos en la provincia de Albacete y se suman un total de 11.000 Ha. más, lo que supone para esta denominación de origen unas $30.000 \mathrm{Ha}$. aproximadamente cultivadas de distintas variedades en donde la monastrell es la más destacada ya que representa más del $80 \%$ de la superficie cultivada, el municipio de Jumilla es el más importante de la Región de Murcia en cuanto a producción vinícola.

15 La aparición de restos arqueológicos lo atestigua, por ejemplo restos ibéricos y romanos en el Paraje de Coimbra del Barranco Ancho. 


\subsection{La «Ruta del vino de Jumilla» y su impacto en la actividad económica de la viticultura}

Tras el previo proceso de acreditación, la ruta del vino de Jumilla fue certificada en el año 2005 por Acevin (Asociación Española de ciudades del Vino). La ruta propone realizar propuestas en los ámbitos de potenciación de la agroindustria, planificación urbanística, cultura y turismo vinícola, patrimonio industrial, creación de instrumentos de promoción local y de diversificación de la actividad económica, de hecho dentro de la propia ruta se han diseñado cinco recorridos clave: Ruta de la ciudad, Ruta de Santa Ana, Ruta de la Pedrera, Ruta del Carche y Ruta de la Cingla, la primera tiene un carácter urbano, las otras cuatro representan el espacio rural y la contemplación del paisaje agrario.

Esta ruta del vino, fue la primera certificada en la Región de Murcia, siguiéndole luego Bullas y Yecla. La colaboración del Ayuntamiento de Jumilla, el Consejo Regulador de la Denominación de Origen y especialmente la iniciativa privada a través de varios bodegueros de la ciudad fueron los elementos decisivos para consolidar y certificar esta ruta que hoy día presenta una gran proyección turística para la ciudad y su término municipal, así como uno de los principales atractivos turísticos del interior de la Región de Murcia.

Sin duda la ruta del vino de Jumilla, ha supuesto un elemento dinamizador para la economía local, suponiendo un total de 22.857 visitas en 2013, que supuso un incremento absoluto de más de 4.000 visitantes con respectos a 2012. Los premios conseguidos, y la vinculación de la población local al vino, desde una perspectiva de «marca territorial», hacen del vino un elemento estratégico y dinamizador de la economía local y así lo ha venido siendo desde hace muchas décadas ya que esta ciudad nunca ha tenido un desarrollo industrial palpable. En la propia morfología urbana y el trazado de las calles la aparición de bodegas y espacios dedicados al vino es evidente. El siglo XXI supone unos cambios socioeconómicos muy relevantes y ello ha provocado la adaptación al nuevo contexto mundial en donde la competitividad y calidad son los elementos diferenciadores del progreso o hundimiento de un sistema económico. Jumilla una agrociudad que ha experimentado cambios sociales profundos con la llegada masiva de población inmigrante, conexión con autovía al corredor mediterráneo e intentos de promoción de grandes espacios residenciales tipo resort que han caído en el fracaso, volviéndose hacia sus bases económicas tradicionales aunque con una necesaria renovación que la hagan viable asegurando el futuro de sus habitantes.

\subsubsection{Remodelación y creación de instalaciones vitivinícolas}

Más de veinte establecimientos de calidad componen la Ruta del Vino de Jumilla: hoteles, bodegas que ofrecen manjares entre barricas, enotecas que son lugares de encuentro y debate sobre el universo del vino, restaurantes donde poder gustar la gastronomía local y regional, etc. Esta intensa actividad en torno al vino ha generado la necesidad de remodelar las bodegas e incluso la construcción de otras de nueva planta y diseño novedoso, lo que ha supuesto un importante esfuerzo de adaptación de un uso exclusivamente dedicado a la elaboración de vinos a espacio de producción de ocio y recreación, por ejemplo en las bodegas se integra a las dependencias dedicadas a 
molturación, fabricación, depósito y embalaje de vino otros espacios como restaurante, tienda de objetos y venta de vinos así como la posibilidad de pasear entre los viñedos en las distintas épocas del año y disfrutar de un paisaje cambiante y cargado de belleza.

En la actualidad figuran once bodegas en la D.O. Jumilla adheridas a la ruta del vino, de las cuales todas figuran como visitables, incluso en tres de ellas existe la posibilidad de disfrutar de la gastronomía local y de los maridajes del vino y platos típicos locales. Las principales actividades que ofrecen son: degustación, celebración de eventos, curso de catas, venta de vinos y productos de la tierra y gastronomía.

\section{Cuadro 3 \\ DISTRIBUCIÓN DE LAS BODEGAS POR MUNICIPIOS EN LA D.O. JUMILLA}

\begin{tabular}{|c|c|}
\hline Municipios & D.O. Jumilla \\
\hline Jumilla & 29 \\
\hline Tobarra & 2 \\
\hline Albatana & 2 \\
\hline Fuenteálamo & 2 \\
\hline Ontur & 3 \\
\hline Montealegre del Castillo & 3 \\
\hline Total & 41 \\
\hline
\end{tabular}

Fuente: Consejo Regulador D.O. Jumilla.

\subsubsection{Patrimonio cultural y turismo enológico}

Se vincula de una forma muy significativa la celebración de fiestas con la exaltación del vino y las tareas agrarias, en el caso de Jumilla, en el mes de agosto coinciden la feria, celebración de Moros y Cristianos y fiestas del vino, no cabe dudas que el conjunto de estos eventos genera para la localidad la visita de turistas y una proyección importante de la misma a nivel regional; la «cabalgata del vino» o la «fuente del vino» son espectáculos de gran atractivo turístico que concentran a miles de personas. También en una pedanía próxima a Jumilla, en la llamada «Fuente del Pino», en el mes de octubre se recrean las denominadas: «Estampas rurales», en donde se presentan las tradicionales actividades del campo antes de la utilización del tractor y demás herramientas posteriores, este evento constituye un gran testimonio etnográfico muy valorado por los visitantes.

En la localidad de Jumilla, se anunció en el año 2012, la intención de crear un gran museo del vino en una superficie de $900 \mathrm{~m}^{2}$, que formaba parte de una antigua bodega y ahora se encuentra en estado de abandono, esta iniciativa museística supone una evidente intencionalidad de fomentar la cultura del vino, de hecho en la ciudad existe un museo etnográfico y en varias bodegas privadas se muestran objetos y utensilios relacionados con la actividad vinícola, también el certamen veraniego de «Música entre vinos» supone un importante y singular aliciente para la difusión de la cultura del vino entre los eventuales visitantes. 
Figura 6

FIESTA DE LA VENDIMIA

EN JUMILLA

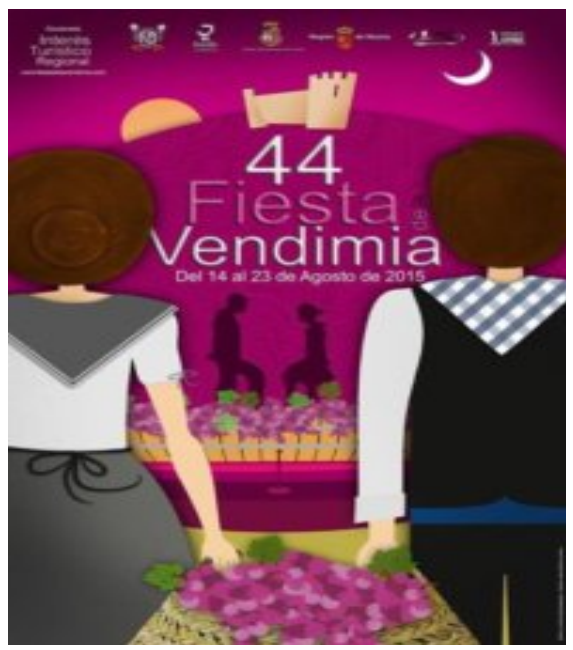

Fuente: Excmo. Ayuntamiento Jumilla.

\section{Figura 7 \\ SEÑALÉTICA DE LA RUTA \\ DEL VINO JUMILLA}
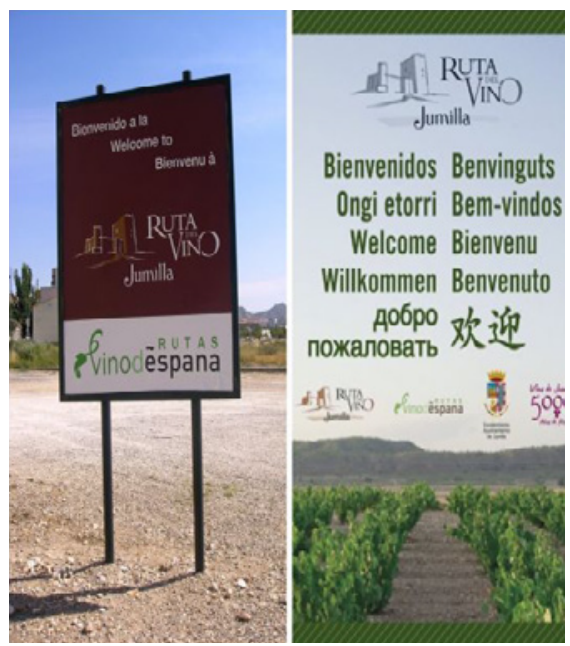

Fuente: Ruta del vino de Jumilla.

\subsubsection{Ampliación de los Recursos hoteleros y espacios gastronómicos}

No se entiende una ruta del vino sin la posibilidad de alojamiento y disfrute de la gastronomía local y regional que suele ir acompañada de los maridajes que ofrecen los distintos vinos existentes, por todo ello a esta ruta se han adherido nueve restaurantes, tres hoteles, dos enotecas, dos bares, una almazara de aceites e incluso comercios especializados como un centro de belleza y una agencia de viajes. No obstante la oferta existente resulta insuficiente para eventos de mayor impacto como podrían ser la puesta en marcha de congresos de carácter nacional o internacional.

\section{Cuadro 4}

\section{RECURSOS HOTELEROS DE LA D.O. DE JUMILLA (AÑO 2013)}

\begin{tabular}{|c|c|}
\hline & D.O. Jumilla \\
\hline $\mathrm{N}^{\mathrm{o}}$ alojamientos hoteleros & 4 \\
\hline Alojamientos rurales & 4 \\
\hline $\mathrm{N}^{\mathrm{o}}$ Plazas alojamientos total & 141 \\
\hline $\mathrm{N}^{\circ}$ de Restaurantes & 13 \\
\hline Bodegas & 29 \\
\hline Bares de vinos & 11 \\
\hline Camping $\mathrm{n}^{\circ}$ plazas & 0 \\
\hline
\end{tabular}

Fuente: Plan Dinamización Turística de Murcia (2007-2013). 


\section{EL DESARROLLO DE LA VITICULTURA Y ACTIVIDAD ENOTURÍSTICA EN LA DENOMINACIÓN DE ORIGEN YECLA}

\subsection{Yecla, una tradición vitivinícola renovada}

El cultivo de la vid se debió introducir en la comarca en época romana, a pesar de la prohibición existente con el fin de proteger la exportación existente de los vinos procedentes de la península italiana, en el Bajo Imperio aparece la vid por toda la Baética y Carthaginense, así lo atestiguan los restos de un lagar hallados en las excavaciones realizadas en el Paraje de «La Fuente del Pinar» datados en el siglo I como el testimonio más concluyente.

Recorriendo la historiografía local, en las relaciones topográficas de Felipe II de 1575 se indica que "existían algunas viñas, pero la producción era tan baja que no cubría el consumo de los habitantes de la villa». (Morales, 1972) señalaba como la producción de vino a lo largo de los siglos XVII y XVIII no está bien indicada, ya que el interés por no pagar los diezmos impuestos por la Iglesia hace que la producción real quedara sin declarar

En el último tercio del Siglo XIX, concretamente en la década de 1870-1880 se efectuaron de forma masiva plantaciones de vid en todo el término municipal, quedando casi todas los cultivos de vid repartidos entre unos 567 agricultores, los cuales cedían las tierras para la plantación de vides, y así llegó el año 1900, en que el esfuerzo de treinta años de trabajo hizo que las tres mil escasas hectáreas se transformaran en unas 15.000 En la última década del siglo XIX terminarán los tratados de exportación con Francia y la economía de Yecla aparecerá estancada aunque se mantendrá el desarrollo alcanzado; se continuaron cultivando las vides y de forma paulatina se hicieron nuevas plantaciones conforme se accedió a nuevas roturaciones de terrenos incultos y baldíos, por la escasez pluviométrica de la zona. Una vez los viñedos franceses pasaron la filoxera, Francia y su colonia de Argelia volvieron a recuperar su producción, Yecla al igual que muchos pueblos de España sufrió una crisis importante, de hecho el apoyo de la exportación quedó en niveles mínimos, hubo una relación causa-efecto de ciudad que se abrió al contexto internacional a través de la exportación de un producto agrícola como es el vino y conoció el auge-caída en un plazo de tiempo relativamente corto (treinta años).

Desde 1950 la viticultura experimentó su mayor expansión dentro de la comarca; evolución frenada a partir de 1986 con la entrada de España en la Unión Europea. Tras la reestructuración del viñedo, ayudas al arranque y puesta en funcionamiento de las tierras más aptas para el cultivo, a partir de la década de los noventa se observa una ligera recuperación que alcanza de nuevo los datos de los años 50. Actualmente el número de hectáreas cultivadas se eleva a unas 13.000 lo que significa un 21,39\% del total de tierras del término municipal.

\subsection{El proceso de creación de la «Ruta del vino de Yecla»}

La denominación de origen de Yecla fue concedida en el año 1975, a lo largo de muchos años se han obtenido muchos premios nacionales e internacionales. Un nuevo 
impulso surgió a partir de 2008 cuando se instituyó el certamen de selección de vinos de la Denominación de origen de Yecla y de cara al turismo enológico, en el año 2009 Yecla se integró en la asociación española de Ciudades del Vino (ACEVIN) impulsora de las rutas del Vino de España. El liderazgo desarrollado por el Ayuntamiento de la ciudad, junto al apoyo del Consejo Regulador de la Denominación de Origen y la iniciativa particular de bodegueros y locales comerciales de restauración y comercio han hecho posible una extraordinaria y rápida promoción que ha desembocado en la certificación de la ruta el 27 de julio del 2013, siendo la ruta certificada número veinte en todo el conjunto del estado español. En los datos ofrecidos por ACEVIN, en cuanto al número de visitantes, en 2013, Yecla ofrecía un total de visitantes de 3.268, que a pesar de la modestia de la cifra, con respecto al año anterior ha supuesto un incremento del $25 \%$.

La ruta del vino de Yecla es un modo de descubrir a través de la cultura del vino los recursos turísticos y gastronómicos del municipio, forman parte como asociados de la misma un total de tres alojamientos, nueve restaurantes, una agencia de viajes, cinco bares de vinos, cinco comercios especializados, cinco bodegas y tres lugares de ocio especializado.

\section{Figura 8 \\ CARTEL ANUNCIADOR DE LA «RUTA DEL VINO DE YECLA»}

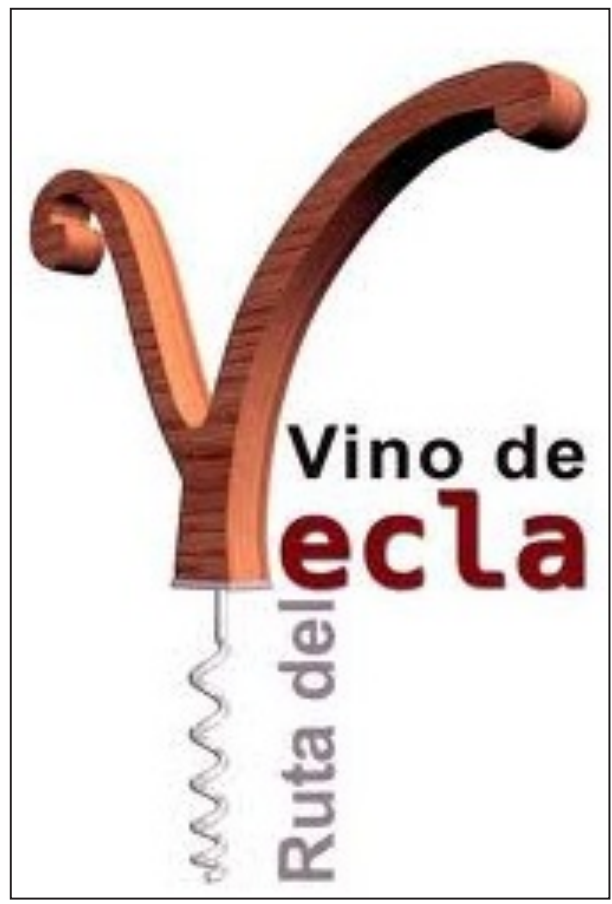

Fuente: Asociación Ruta del Vino de Yecla.

\section{Figura 9 \\ CARTEL ANUNCIADOR FERIA DEL VINO DE YECLA}

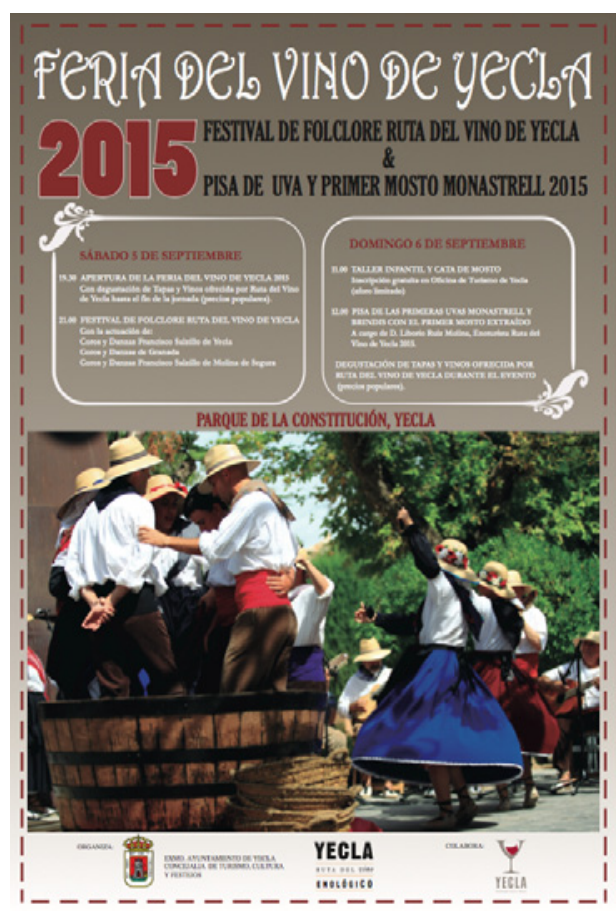

Fuente: Asociación Ruta del Vino de Yecla. 


\subsection{Repercusión de la ruta del vino y viticultura en el desarrollo local de la ciudad}

El desarrollo de la globalización de la economía y en general de la sociedad, está influyendo notablemente en la transformación del paisaje, tanto urbano como rural (Morales, 2012). De hecho fotografías, planos catastrales y otros soportes documentales aportan un fuente sólida de estudio y confirman la gran transformación experimentada por el espacio objeto de estudio en menos de tres décadas. La actividad agraria desarrollada en el contexto de la globalización potencia la aparición de una agricultura tecnificada, adaptada a la competitividad comercial y por tanto al ajuste de calidad/precio; este hecho repercute en el paisaje de forma muy palpable: extensión de nuevos regadíos, aparición de maquinaria sofisticada, y diversificación de la mano de obra así como la aparición de personal cualificado en diversas facetas: contabilidad, manejo de maquinaria, programadores informáticos para los regadíos, etc.

También el paisaje está cambiando debido a la aparición de actividades terciarias que nada tienen que ver con la agricultura y ganadería, como son los alojamientos rurales o las segundas residencias, muy demandadas ante la necesidad de los ciudadanos de «abandonar el espacio urbano», al menos los fines de semana. El enoturismo no deja de ser una actividad económica, lo que conlleva un uso del suelo y por tanto una transformación del espacio agrícola y urbano de los lugares en los que se desarrolla. En el caso del término municipal de Yecla, observamos importantes cambios que vendrían a sintetizarse en diversos aspectos desarrollados a continuación.

\subsubsection{Transformaciones en las instalaciones vitivinícolas}

La remodelación de bodegas o construcción de nueva planta supone un gran esfuerzo de adaptación de un uso exclusivamente dedicado a la elaboración de vinos a espacio de producción de ocio y recreación, por ejemplo en las bodegas se integra a las dependencias dedicadas a molturación, fabricación, depósito y embalaje de vino con otros espacios como restaurante, tienda de objetos y venta de vinos, en la actualidad figuran once bodegas en la D.O. Yecla adheridas a la ruta del vino, de las cuales cinco figuran como visitables, incluso en dos de ellas existe la posibilidad de disfrutar de la gastronomía local.

\subsubsection{Vinculación de «Las rutas del vino» a la visita del patrimonio local}

La visita a cada ruta del vino significa conocer y disfrutar el patrimonio local de la zona, se asocia a las diferentes rutas los principales museos, actos culturales o monumentos de interés histórico artístico que para el caso de Yecla son notables. Existe una conexión muy acertada entre la cultura del vino y la contemplación de los paisajes generados, así como un claro aprovechamiento en la visita a yacimientos arqueológicos puestos en valor como la villa romana de Torrejones, la ciudad musulmana de Yakka o las pinturas rupestres y petroglifos y cazoletas del enigmático monte Arabí. También los diversos monumentos existentes en el casco urbano y diversos espacios museísticos complementan el disfrute de la variedad gastronomía y la degustación de los vinos de 
la tierra. Disponemos de datos de la oficina de turismo que indican el ascenso de la actividad turística debida a la actividad relacionada con el enoturismo (cuadro 5).

\section{Cuadro 5 \\ TIPOS DE ACTIVIDAD TURÍSTICA EN YECLA (EN \%)}

\begin{tabular}{|l|l|r|}
\hline Año & Tipo de actividad & $\%$ \\
\hline 2005 & Cultura & 62,90 \\
& Eventos Deportivos & 39,40 \\
& Enoturismo & 7,98 \\
& Otros & 11,23 \\
\hline 2008 & Cultura & 51,70 \\
& Eventos Deportivos & 15,21 \\
& Enoturismo & 12,18 \\
& Otros & 20,89 \\
\hline 2012 & Cultura & 44,89 \\
& Eventos Deportivos & 22,25 \\
& Enoturismo & 10,94 \\
& Otros & 11,50 \\
\hline 2014 & Cultura & 50,20 \\
& Eventos Deportivos & 23,10 \\
& Enoturismo & 17,20 \\
& Otros & 9,50 \\
\hline
\end{tabular}

Fuente: Oficina de Turismo de Yecla.

\subsubsection{Ampliación de los Recursos hoteleros y espacios gastronómicos}

El sector hostelero de las denominación de origen de Yecla presenta grandes contrastes entre los lugares dedicados a las restauración y bares de vinos con la capacidad de

\section{Cuadro 6}

\section{RECURSOS HOTELEROS DE LA D.O. DE YECLA (AÑO 2013)}

\begin{tabular}{|l|c|}
\hline & D.O. Yecla \\
\hline $\mathrm{N}^{\circ}$ alojamientos hoteleros & 2 \\
\hline Alojamientos rurales & 3 \\
\hline $\mathrm{N}^{\circ}$ Plazas alojamientos total & 158 \\
\hline $\mathrm{N}^{\circ}$ de Restaurantes & 18 \\
\hline Bodegas & 11 \\
\hline Bares de vinos & 14 \\
\hline Camping $\mathrm{n}^{\circ}$ plazas & 0 \\
\hline
\end{tabular}

Fuente: Plan Dinamización Turística de Murcia (2007-2013). 
alojamientos para pernoctar, abundan los primeros frente a una clara insuficiencia de los segundos, ello provoca la creación de un turismo de día, con un nivel de estancias muy corto, que no supera la media de 6 horas (Plan estratégico del turismo de Murcia). Los establecimientos hoteleros existentes tampoco son de gran nivel puesto que no existe ningún hotel entre tres y cinco estrellas, ello constituye una gran área de mejora para atraer un turismo estable que al permanecer más tiempo genere un mayor gasto y repercusión económica más amplia.

\subsubsection{Patrimonialización de las fiestas dedicadas al vino}

En el municipio de Yecla, las fiestas dedicadas al vino se celebran en el mes de mayo coincidiendo con las denominadas «Fiestas de San Isidro», destaca la cabalgata de carrozas engalanadas con motivos rurales y el concurso de catas de vino siempre asociado a la gastronomía local, la ciudad en estos días duplica la población, lo que genera un importante movimiento económico en el sector hostelero, al mismo tiempo los visitantes tienen la oportunidad de conocer el patrimonio histórico-artístico de la ciudad, destacando las visitas a museos y edificios singulares sin olvidar el importante impacto económico sobre los lugares de ocio y gastronomía en eventos como «La ruta de la tapa» o degustación de los productos y platos típicos de las ciudad. Por el momento sólo se trata de un evento temporal que necesita ampliarse de forma más amplia a lo largo del año rompiendo la actual temporalidad.

\section{ANÁLISIS DAFO}

Con la finalidad de completar el análisis, elementos positivos y aspectos a mejorar, valorando de esta forma las sinergias de las rutas del vino, se ha realizado un análisis DAFO que es una herramienta eficaz para el análisis de estudio de la situación de una empresa o un proyecto, analizando sus características internas (debilidades y fortalezas) y su situación externa (amenazas y oportunidades) en una matriz cuadrada. Proviene de las siglas en ingles SWOT (strengths, weaknesses, opportunities y threats), es una herramienta para conocer la situación real en que se encuentra una organización, empresa o proyecto, y planear una estrategia de futuro. También permite la participación de distintos grupos de interés, ya que los participantes en las entrevistas son expertos o conocedores de la investigación llevada a cabo, lo que indica suficientes garantías de fiabilidad en las respuestas, y ello se incrementa con las respuestas llegan a un índice de saturación alto (por encima del 90\% de coincidencias). De la combinación de fortalezas con oportunidades surgen las potencialidades, las cuales señalan las líneas de acción más prometedoras para la organización. Las limitaciones, determinadas por una combinación de debilidades y amenazas, colocan una seria advertencia mientras que los riesgos (combinación de fortalezas y amenazas) y los desafíos (combinación de debilidades y oportunidades), determinados por su correspondiente combinación de factores, exigirán una cuidadosa consideración a la hora de marcar el rumbo que la organización deberá asumir hacia el futuro deseable. (Cuadro 7). 
Una vez finalizados los análisis parciales (definidos los objetivos sobre el que se desarrolla el estudio y realización del trabajo de campo para conocer la realidad de sobre el que vamos a hacer dicho estudio), éstos permitirán realizar un diagnóstico de las debilidades, amenazas, fortalezas y oportunidades para, a continuación, y en función de este análisis, establecer unos objetivos, proponer diferentes estrategias de desarrollo capaces de superar los condicionantes identificados y alcanzar los objetivos de conocimiento del modelo de desarrollo enoturístico de las comarcas estudiadas. El análisis interno (puntos fuertes y débiles) examina en profundidad cada uno de los componentes que configuran las características internas de la puesta en valor de las instalaciones mineras con el propósito de identificar puntos fuertes y débiles en la organización de las mismas, la realización de nuevos proyectos o el rendimiento en cuanto a visitas existentes.

\section{Cuadro 7 \\ Matriz DAFO}

\begin{tabular}{|c|c|c|}
\hline & Oportunidades & Amenazas \\
\hline 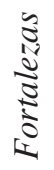 & $\begin{array}{l}\text { ¿Qué oportunidades externas pueden ser } \\
\text { aprovechadas por las fortalezas internas }\end{array}$ & $\begin{array}{l}\text { ¿Qué amenazas externas pueden ser } \\
\text { contrarrestadas por las fortalezas } \\
\text { internas? }\end{array}$ \\
\hline 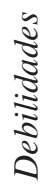 & $\begin{array}{l}\text { ¿Qué oportunidades externas pueden ser } \\
\text { aprovechas si se superan las debilidades } \\
\text { internas? }\end{array}$ & $\begin{array}{l}\text { ¿Qué amenazas externas no pueden } \\
\text { ser contrarrestadas si no se superan las } \\
\text { debilidades internas }\end{array}$ \\
\hline
\end{tabular}

Fuente: Cánoves, G., Villarino, M., Blanco Romero, A., De Uña, E. y Espejo, C. (Eds.) (2014): Turismo de interior: renovarse o morir.

A través de entrevistas a 15 establecimientos de las tres rutas aquí estudiadas. Mediante esta herramienta se ponen de relieve las debilidades que presentan en este sector de actividad económica y las amenazas que sufre. En la situación actual es difícil, pero los entrevistados afirman en la necesidad de seguir potenciando el club de producto, rutas del vino, favorecer acuerdos entre todas los agentes implicados (restaurantes, bodegas, alojamientos, tiendas especializadas, AA.VV., ayuntamientos y entidades supralocales), al objeto de favorecer mayores sinergias. También se incide en mejorar la señalética y en establecer actividades y acciones de visibilidad y sensibilización sobre aspectos vinculados a la cultura del vino. Además, los datos obtenidos han dado una visión aproximada y real, más allá de las estadísticas, de la actual situación del sector. Salvo excepciones la participación de los encuestados ha sido plena. A continuación señalamos los resultados obtenidos, que esperamos puedan servir de referencia como un análisis actual y de proyección futura. 


\section{Cuadro 8 \\ DEBILIDADES DEL SECTOR DEL VINO EN LA COMARCA DEL VINALOPÓ, YECLA Y JUMILLA}

1. La imagen de los vinos del SE español es poco conocida a nivel internacional, aunque la venta de vinos ha llegado a países como EE.UU., Japón o Australia y continua siendo el mercado nacional el principal cliente, ello repercute directamente en que existan pocas visitas a las rutas del vino por parte de extranjeros

2. Todavía más de la mitad de bodegas no tiene previstas las visitas ni han acondicionado sus instalaciones para esta actividad complementaria

3. Existe poca difusión a nivel de prensa y marketing de las rutas del vino del SE español, de hecho faltan esfuerzos para una adecuada señalización tanto en las ciudades como en las posibles zonas en el medio rural.

4. El escaso turismo que visita estas zonas no tiene como prioridad la cultura del vino ya que existen otros atractivos de más peso como son los monumentos o museos.

5. La actual crisis económica está perjudicando la llegada de fondos públicos y privados que incidan en la promoción turística de este sector.

6. A pesar de los esfuerzos realizados se detecta todavía una carencia de profesionales y guías turísticos especializados en la cultura del vino. Falta de acciones de sensibilización a la población local, en este sentido.

7. La capacidad hotelera de las rutas del vino es baja y tampoco se prevé en el futuro la construcción de nuevos alojamientos tanto urbanos como rurales, ello repercute en un turismo de visita diaria, en donde las pernoctaciones son muy escasas, lo que sin lugar a dudas perjudica al sector hostelero y de restauración.

8. Mejora de la señalética y falta de colaboración entre los distintos establecimientos, que no favorece sinergias.

\section{Cuadro 9 \\ AMENAZAS DEL SECTOR DEL VINO EN LA COMARCA DEL VINALOPÓ, YECLA Y JUMILLA}

1. La visita a bodegas tiene un carácter limitado, ya que el acceso a las mismas queda en muchos casos restringido a la llegada de profesionales y clientes, no al público en general. Faltan infraestructuras adecuadas para garantizar la recepción de visitantes.

2. La imposibilidad en estos momentos de crisis de articular un proyecto turístico de la cultura del vino de gran eficiencia y de importantes resultados económicos y laborales.

3. El enoturismo se está convirtiendo en un sector que se extiende por todo el territorio nacional, puede darse el caso que las zonas más conocidas y con mayor nombre eclipsen otras rutas menos conocidas o poco desarrolladas.. 
4. La actual crisis económica influye en falta de subvenciones y ayudas públicas para el diseño y puesta en valor de las rutas del vino.

5. El enoturismo puede verse perjudicado por otras modalidades turísticas existentes en la zona, esencialmente por el turismo de sol y playa que nunca rebasa los 60 minutos de desplazamiento, cuestión que puede influir en la decisión final de los visitantes.

6. Cercanía de denominaciones de origen y rutas del vino con más fama, arraigo y publicidad.

\section{Cuadro 10 \\ FORTALEZAS DEL SECTOR DEL VINO EN LA COMARCA DEL VINALOPÓ, YECLA Y JUMILLA}

1. El paisaje agrario de las comarcas se mantiene conservado y ofrece un buen atractivo visual a lo largo de las diversas estaciones del año

2. En las tres rutas del vino se organizan a lo largo del año una serie de eventos y fiestas de gran arraigo relacionadas con la cultura del vino.

3. En los últimos años se ha hecho un gran esfuerzo en la recuperación de espacios etnográficos como sería el museo del vino en Bullas o la recuperación de bodegas en Jumilla y Yecla. También en el caso de Alicante, Villena ha entrado en los circuitos turísticos de «ciudades AVE», potenciando la ruta del Vino

4. En las nuevas generaciones de bodegueros aparece una mentalidad empresarial en donde se tiene en cuenta la dimensión comercial de visitas turísticas y marketing de empresas.

5. Existe una tradición vinícola arraigada, el sector del vino forma parte de la cultura de estas comarcas y ha tenido continuidad en diversas épocas históricas.

6. Alta calidad de los viñedos que existen en la zona, que en los últimos años han favorecidos las respectivas D.O.

7. Riqueza cultural, gastronómica y paisajística, en la que se han implicado en potenciar las empresas y las administraciones locales y provinciales.

\section{Cuadro 11 \\ OPORTUNIDADES DEL SECTOR DEL VINO EN LA COMARCA DEL VINALOPÓ, YECLA Y JUMILLA}

1. La voluntad decidida de los ayuntamientos e instituciones públicas por impulsar el turismo del vino como el producto estrella de estas comarcas.

2. La aparición de nuevos operadores especializados en turismo enológico, aunque de escasa dimensión.

3. El desarrollo de planes de Dinamización Turística/ Producto específicos sobre el turismo del vino. 
4. La integración de las tres denominaciones en el proyecto Rutas del Vino de España

5. Compatibilidad del turismo del vino con otros productos emergentes en ambas regiones y con la actividad de turismo de interior

6. Mejorar los esfuerzos y la colaboración entre las D.O. y las rutas del vino, al objeto de favorecer marcas territoriales alrededor de la cultura del vino de cada uno de los territorios analizados.

7. Intentar captar más visitantes, procedentes de la costa (tanto turistas como residentes), al objeto de captar extranjeros con mayor poder adquisitivo.

El análisis DAFO refleja claramente que el sector del enoturismo en estas comarcas puede constituirse en un importante elemento de dinamización socioeconómica y constituye un sistema productivo local de gran proyección económica. Por ello es necesaria una adecuada promoción de esta actividad que se adapte al paisaje agrario y a la tradición agrícola, incorporando el turismo, como una actividad de revalorización de los recursos locales, y de diversificación productiva. Para ello es importante la unión de iniciativas comunes, la formación de los agentes implicados y la colaboración entre empresas privadas, ayuntamientos, diputaciones y Consejerías de Agricultura y Turismo.

\section{CONCLUSIONES}

En febrero 2014, ACEVIN presentó un nuevo informe sobre la demanda de las rutas del vino en España. Fue un quinto informe realizado durante los meses de octubre y noviembre de 2013, en siete territorios ecoturísticos. Así se observa que el 25,4\% de las reservas se hacen por Internet, el 25’3\% visitan las bodegas, sin haber hecho antes una reserva previa. En cuanto a las motivaciones que impulsan a los visitantes a acercarse a los territorios enoturísticos de España, los resultados generales apuntan a que el $48 \%$ son las visitas a bodegas, la gastronomía supone un 44,9\%, y más lejos aparecen el patrimonio y la cultura vitivinícola con un 31,8\%. El vehículo privado sigue siendo el medio de desplazamiento general, y el periodo de estancia ha descendido, con respecto a 2010, con 2,1 días, frente a los 2,4 días del informe anterior. El alojamiento sigue siendo los hoteles de cuatro estrellas, pero la novedad reside en que en 2013 ha descendido los alojados en casas y hoteles rurales, pasando a tener un $8,7 \%$ en 2013 , frente a los $14,1 \%$ que tuvo en 2010. Otro dato a destacar es el nivel de gasto de las personas encuestadas en este estudio de ACEVIN (que fueron en total 708 personas de siete territorios vitivinícolas). El gasto medio diario de los enoturistas fue de $85,4 €$, que representa un descenso de $21 €$, con respecto a los datos de 2010 , que registró $107 €$. Además se produce una notable diferencia entre el gasto medio diario de los españoles $(77,8 €)$ y de los extranjeros $(104,5 €)$. Aún así, el enoturismo sigue siendo una fuente importante de ingresos, pues el gasto de los enoturistas españoles es superior al gasto medio diario de los turistas españoles $(77,8$ $€$ frente a $31,9 €$, según datos de FAMILITUR y EGATUR)

Por todo ello el enoturismo es una gran apuesta para diversificar la economía en estas comarcas, de hecho la actividad comercial, hostelera y de restauración en general se puede 
ver beneficiada y cubrir el actual déficit del sector industrial, en las comarcas del Vinalopó, en Yecla y Jumilla, que se encuentra en retroceso por la actual crisis económica global en la que nos encontramos inmersos.

La potencialidad del turismo rural, liderada por el enoturismo (Monnier, 2010) se perfila como un sector estratégico ya que está influyendo en aspectos como la visita a bodegas (Zárate, 2010) y posterior venta de productos, mayores ingresos en el sector hostelero y visita a lugares de interés cultural (Duboscq, 2010) que no han terminado de potenciarse en épocas anteriores y que son los puntos fuertes de este turismo de interior.

$\mathrm{Si}$ algunos vinos gozan de buena salud, tal situación no puede generalizarse a todo el Estado Español. Además, en general, en la DO de Alicante, Yecla y Jumilla, la mejora de la calidad no ha compensado la pérdida constante de extensión y beneficios, en cuanto a lo que viticultura se refiere. De ahí la importancia de explorar iniciativas como el enoturismo, desde un planteamiento integrado. No obstante hay que significar que tan sólo algunas bodegas han conseguido abrirse camino en ese necesario proceso de especialización cualitativa, si bien, buena parte de las mismas están apoyadas en capitales exógenos al mundo de la vid (sobre todo en las comarcas del Vinalopó). Así, algunos de los modelos de explotación incorporados de enoturismo en la provincia de Alicante, no son los más representativos en la zona. A pesar de ello, creemos que el turismo del vino, se está desarrollando de manera pausada, muy ligado a la nueva cocina, a nuevas ofertas turísticas, a la experiencia personal, al gusto por lo auténtico, al patrimonio, al paisaje, a la cultura de un lugar, gracias al trabajo ejercido desde las rutas del Vino de España, que podemos ir identificando en Yecla y Jumilla, aunque de forma más aislada en las comarcas del Vinalopó (Alicante).

La presente investigación ha tenido la finalidad de presentar la situación de partida del enoturismo, y las oportunidades territoriales en el marco de las certificaciones de las rutas del Vino en las zonas especificadas, pero tan sólo desde la perspectiva de las bodegas que forman parte de las susodichas rutas y las posibles conexiones con otros recursos del territorio. La intención es seguir profundizando y plantear en otro estudio, elementos vinculados a la valoración de la demanda, que aquí no se han contemplado.

La certificación en las rutas de Jumilla, Yecla y Alicante ha sido un proceso arduo pero efectivo debido a la unidad de los actores participantes. Del análisis DAFO y de las entrevistas a las Bodegas destacamos la necesidad de una mayor conexión entre las tres denominaciones de origen para crear una ruta del vino intercomarcal que ponga en contacto las tierras del norte de Murcia y las comarcas del Vinalopó que pueda generar flujos turísticos, más allá de las posibilidad del turismo de «sol y playa». En la provincia de Alicante los ayuntamientos implicados en este proyecto de la Ruta del Vino, están encontrando dificultades para desarrollar un modelo turístico basado en el turismo de interior y enogastronómico. Ello se debe en parte, al limitado conocimiento que existe sobre los caldos de la zona, la ausencia de formación en conceptos enoturísticos por parte de las empresas privadas, la escasa financiación tanto pública (tras la disminución por parte de los ayuntamientos de sus partidas económicas destinadas a la promoción turística) como privada y la falta de sensibilización e implicación por parte de la población local. Así a excepción de Jumilla y Yecla, las Comarcas del Vinalopó tienen que hacer mayores esfuerzos para promocionar y visibilizar sus vinos a través de actividades y acciones conjuntas 
(D.O. ayuntamientos y bodegas). Además, no todas las bodegas gozan de instalaciones adecuadas para favorecer una visita turística. A ello se añade la falta de señalética específica y personal cualificado en materia de turismo (guías y gestores de rutas), ya que son muy pocas las bodegas que disponen de ellos.

A su vez, lo que prima en los tres territorios estudiados, es el excursionismo, y no el turismo, siendo uno de sus limitaciones la falta de infraestructuras de alojamiento suficientes. La consolidación de productos enoturísticos, también es insuficiente, porque sólo algunas bodegas han sabido capitalizar y articular una oferta, que sólo beneficia a su propiedad, pero que no ejerce de catalizador para el resto del territorio. De ahí la necesidad de mejorar la colaboración entre las bodegas que conforman las distintas rutas del vino. Eso se podría realizar a través de eventos y patrocinios donde las diferentes bodegas colaboraran entre sí, como los festivales de música que se hacen en Jumilla o el maridaje entre cata de vinos de las diferentes bodegas de la ruta del Vino de Alicante y el teatro que se hace en Villena (Teatro Chapí). También establecer pack y productos turísticos combinados, y en colaboración con otros stakeholders del territorio, como hacen algunas bodegas en Alicante (Francisco Gómez, Heretat de Cesilia y BOCOPA). La tradición vinícola en estos territorios está muy arraigada y ello constituye una ventaja, en relación a la tradición y oficio, pero quizás también un handicap, en relación a ver la producción y comercialización del vino, más allá de la actividad agrícola. De ahí la importancia de acciones de sensibilización, formación y networking que se hacen desde las gerencias de las tres rutas del vino analizadas.

\section{Figura 10 \\ PACK ENOTURÍSTICO Y JORNADAS GASTRONÓMICAS}
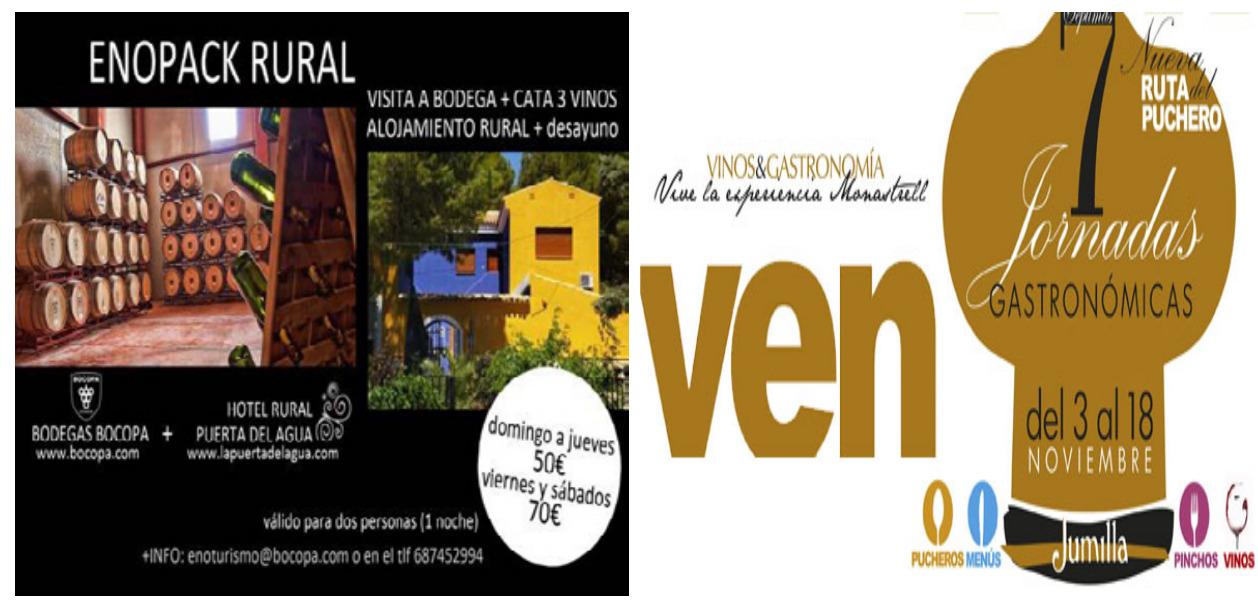

Fuente: Bocopa (Petrer-Alicante). www.elecodejumilla.es

Las oportunidades son muchas, ya que hay un firme compromiso de las administraciones locales y supralocales, y también por las bodegas de ir articulando rutas de vino integradas y en coordinación con el resto de recursos turísticos que los municipios ofrecen. En este sentido sería aconsejable que los organismos gestores de turismo, dirigieran 
sus esfuerzos a micro zonas vinícolas con identidad propia, vinculando bodegas con eventos especializados. Estos paquetes turísticos podrían incluso presentarse en un mismo folleto turístico que englobara toda la oferta turística de cada área vinícola. La Figura 10 refleja la conexión del turismo enológico con otros tipos, como el turismo rural y el turismo gastronómico (Brunori y Rossi, 2000). Esta vinculación se debería formalizar con la firma de acuerdos entre empresas y en la realización de actividades transversales, que tengan como denominador común el vino. Por ejemplo, con empresas de restauración, conectando con el turismo gastronómico (Frochot, 2003), o de actividades de turismo activo, vinculando el turismo enológico con el de naturaleza y cultural. Todo ello con la colaboración de Ayuntamientos y otros organismos públicos que intervienen en las acciones turísticas, así como entidades vinculadas directamente con el vino, como son los Consejos Reguladores, en ocasiones distantes a lo que significa la cultura del vino y sus posibilidades turísticas. Otro aspecto importante se refiere a la personalización de los paquetes turísticos según el gasto turístico de cada segmento de demanda, que es un aspecto a considerar en la próxima investigación.

Por último y en el contexto de la presente investigación exploratoria y cualitativa, podemos establecer acciones de prescripción que podrían revertir en un beneficio común y comunitario para las tres rutas del vino analizadas:

- Fomentar la cultura del vino, principalmente, en los bares y restaurantes, incluso a través de cursos de formación entre los propios restauradores (exposición de los vinos en los establecimientos, mensajes publicitarios promocionando el vino de Yecla, Murcia y Alicante etc.); jornadas gastronómicas con productos de la región Murciana y Valenciana; o promoción de vinos en eventos como inauguraciones de nuevos restaurantes, casas rurales o inauguración de exposiciones u obras de teatro. Esta creación de un mundo en torno al vino también se debería difundir mediante la exposición privilegiada de los vinos de Yecla, Jumilla y Alicante en los centros comerciales u otros establecimientos comerciales; a través de talleres enológicos con niños, para que tomen contacto con la materia prima y conozcan el proceso de elaboración; o bien participando en cursos de sumilleres y restauración, libros de cocina o encuentros empresariales del sector hotelero o de la restauración con otros empresarios y asociaciones vinculadas a la cultura, la historia, el turismo deportivo.

- Realizar acuerdos entre bodegas y establecimientos hoteleros, casas rurales u otros alojamientos, como medio de captación de visitantes, ya que los que existen no son suficientes, y reforzar esta relación más allá de la placa que ponen en algunos establecimientos que indica que pertenece a la Ruta del Vino.

- Firmar acuerdos con agencias de viaje y con empresas que comercializan paquetes turísticos bajo la denominación de cajas-tarjetas regalo como Smart Box, La vida es bella o Plan B.

- Formalizar acuerdos con bodegas de otras denominaciones de origen con mayor tradición enoturística, como La Rioja o Ribera del Duero, ofertando descuentos u ofertas especiales para dar a conocer las bodegas de Alicante, Yecla y Jumilla como opción enoturística, utilizando la marca paraguas de Rutas del vino de España, y el networking que se establece en este club de producto. 
- Llevar a cabo jornadas de puertas abiertas en las bodegas con exposiciones de pintura, fotografía, conciertos, teatro, etc., con el objetivo de fusionar distintos tipos de actividades, ya que son muy pocas las bodegas que llevan a cabo estas iniciativas.

Finalmente significar que como en todo estudio, esta investigación no está exenta de limitaciones, que generan algunas de las líneas futuras de investigación. En primer lugar, se ha intentando realizar un estudio exploratorio, identificando los aspectos generales de los que participa las rutas del vino, y por extensión su ajuste a las zonas objeto de estudio (Vinalopó y Altiplano Murciano), analizando su evolución hasta constituirse en rutas del vino certificadas. Luego se ha realizado una segmentación teniendo en cuenta sólo algunas bodegas que forman parte de la ruta del vino, analizando el contexto espacial en el que se situaban. Sin embargo en esta segmentación no se han tenido en cuenta otras variables de interés como por ejemplo la perspectiva de los visitantes, ni su procedencia, ni sus motivaciones, así como tampoco hemos incluido a empresas, vinotecas o establecimientos que forman parte de la ruta del vino. Nuestro interés ha residido en las bodegas que forman parte de las rutas del vino, pero no en la totalidad de las que forman parte de las Denominaciones de Origen. En segundo lugar, significar que hay intención de intensificar el estudio de campo para complementar el análisis descriptivo aquí realizado, y que cuantifique y cualifique a los visitantes de las principales bodegas, en diferentes periodos del año, así como su procedencia, ya que seguimos manteniendo que esta tipología turística, vinculada al enoturismo, supone una oportunidad que cumple la teoría de larga cola (long tail), en el área de influencia del sol y playa del que participa el territorio analizado. Ya que el enoturismo puede generar valor favoreciendo la fidelización de clientes (también desde el punto de vista de consumidores de vino), aprovechando recursos existentes en el territorio, optimizando infraestructuras y consolidando productos turísticos basados en lo vivencial, experiencial y diferencial.

\section{BIBLIOGRAFÍA}

ALONSO J.L. (2003): «Redes y procesos de innovación en las comarcas vinícolas de Castilla y León: el ejemplo de la D.O. Bierzo». Boletín de la Asociación de Geógrafos Españoles, $\mathrm{n}^{\circ} 36$, pp. 43-60.

ANDRÉS, J.L. (2000): «Aportaciones básicas del turismo al desarrollo rural». Cuadernos de Turismo, $\mathrm{n}^{\circ} 6$, pp. 45-59.

ANDREU, R. y VERDÚ, L. (2012): «Turismo enológico en Alicante: La ruta del vino en el municipio de Pinoso», Cuadernos de Turismo, $\mathrm{n}^{\circ}$ 30, pp. 35-61.

ASERO, V. y PATTI, S. (2009): «From wine production to wine tourism experience. The case of Italy». American Asociation of Wine Economics. Consultada en www.wineeconomics.org el 11 de Febrero de 2013.

BONIFACE, P. (2003): Tasting Tourism: Travelling for Food and Dirnk, Ashgate Publishing Ltd, Aldersot,

BRUNORI, G. y ROSSI, A. (2000): «Synergy and coherence through collective action: some insights from wine routes in Tuscany», Sociologia Ruralis, vol. 40 (4), pp. 409423. 
CÁNOVES, G., HERRERA L. y VILLARINO, M. (2005): «Turismo rural en España: paisajes, nuevos usos y nuevas visiones», Cuadernos de Turismo, no 15. pp. 63-76.

CÁNOVES, G., HERRERA, L. y BLANCO, A. (2005): «Turismo rural en España: un análisis de la evolución en el contexto europeo», Cuadernos de Geografía, no 77, pp. 41-58.

CÁNOVES, G., VILLARINO, M., BLANCO ROMERO, A., DE UÑA, E. y ESPEJO, C. (Eds.) (2014): Turismo de interior: renovarse o morir. Valencia, Universitat de Valencia, $241 \mathrm{pp}$.

DUBOSCQ, M.CH. (2010): «La comercialización del enoturismo en Francia». Libro de actas del $2^{\circ}$ Congreso Europeo de Turismo industrial. Toledo 2008. pp. 186-191

FROCHOT, I. (2003): «An analysis of regional positioning and its associated food images in French tourism regional brochures», Journal of Travel and Tourism Marketing, vol.14 (3), pp. 77-96.

GOYET, P. (2010): «El turismo vitivinícola: el caso de Francia». Libro de actas del $2^{\circ}$ Congreso Europeo de Turismo industrial. Toledo 2008. pp. 171-177

JIMENEZ, P (1865): Memoria de apuntes para la historia de Yecla.

JOVER , M.J. (2009): «Las rutas del vino como ejemplo de desarrollo local y turístico integrado. Algunas consideraciones sobre la provincia de Alicante», en Martínez Puche, A., Soler Foret, J. L., Larrosa Rocamora, J. A. y Jover Soro, M.J., (Coords.) Desarrollo local, recursos culturales y planes de dinamización de producto turístico en los espacios de interior. Análisis de políticas y escenarios futuros. Alicante: Ed. Plan de Dinamización de Producto Turístico de Villena y Departamento de Geografía Humana de la Universidad de Alicante, pp. 106-119.

LÓPEZ, T.J. y SÁNCHEZ, S.M. (2008): «La creación de productos turísticos utilizando rutas enológicas». Pasos. Revista de Turismo y Patrimonio Cultural, vol. 6, nº 2, pp. 159-171.

LONG, L.M. (2004) (Ed.): Culinary tourism, University Press of Kentucky, Lexington.

MADERA, P. (2006): Hoteles con viñedo. Madrid: El tercer hombre. Madrid.

MARQUEZ, J.C. (1999): El comercio romano en el Portus Ilicitanus, Alicante, Universidad de Alicante e Instituto de Cultura «Juan Gil-Albert».

MARTÍNEZ ,A. (1999): Villena: Industrialización y cambio social (1740-1940). Alicante, Universidad de Alicante.

MARTÍNEZ, A. y JOVER, M.J. (2012): «Cine y enoturismo: Representación, identidad y promoción de los territorios del vino», en Martínez, A., Martínez, S. y Prieto, A. (Eds.), Territorios de cine. Desarrollo local, tipologías turísticas y promoción, Publicaciones Universidad de Alicante, Alicante, pp. 199-220.

MARTÍNEZ, A. (2013): «Turismo de interior, identidad y cultura glocal. Valoraciones y propuesta», Melgosa Arcos, F.J. (Coord.), Turismos de interior, ed. Síntesis, Madrid, pp. 43-77.

MARTÍNEZ, A. (2014): «La ruta del vino en la provincia de Alicante ¿Oportunidad u oportunismo?», en López Palomeque, F. y Cánoves Valiente, G. (Coords.), Turismo y Territorio. Innovación, renovación y desafios, Tirant Humanidades, Barcelona, pp. 503-513.

MATELLANES, M. (2008): Gestión del enoturismo en la D.O. Ribera del Duero de España. Directores: Dr. Salvador Hernández Navarro y Dra. Adriana Corrêa Guimarâes. Tesis doctoral para optar al grado de Doctora por la Universidad de Valladolid. Universidad de Valladolid. 
MADOZ, P (1850): Diccionario Geográfico Estadístico Histórico, Tomo IX, Madrid MOLINA, A., GÓMEZ, M. y ESTEBAN, A. (2013): «Identificación de segmentos de visitantes en zona vinícolas de La Mancha», Papers de Turisme, $\mathrm{n}^{\circ}$ 53, pp. 1-17.

MONNIER, J.M. (2010): «La profesionalización del turismo vitivinícola: el ejemplo del Loira». Libro de actas del $2^{\circ}$ Congreso Europeo de Turismo industrial. Toledo 2008. pp. 179-185.

MORALES, A. (1972): El Altiplano de Jumilla-Yecla. Murcia, Universidad de Murcia, 467 pp. MORALES, F.J. (2005): Efectos de la globalización en la actividad económica de Yecla. Yecla, Ayuntamiento de Yecla, 228 pp.

MORALES, F.J. (2008): Agua y paisaje en Yecla, Yecla. Ayuntamiento de Yecla.

MORALES, F.J. (2012): «Redes y procesos de innovación turística en las comarcas vitivinícolas de la región de Murcia: las rutas del vino y sus consecuencias en la transformación del paisaje», en Actas V congreso desarrollo Local. AGE. Sevilla.

MORALES, F.J. (2013): «La potenciación del espacio rural como motor de desarrollo local, ante la actual crisis industrial en la comarca del Altiplano (Murcia), en Actas VI congreso desarrollo Local. AGE. Alicante.

RICHARDS, G. (2002): «Gastronomy: An essentials ingredient in tourism production and consumption?», en Hjalager, A.M. y Richards, G. (Eds.), Tourism and gastronomy, Routledge, London, pp. 226-237.

SANCHEZ, J.L. (2003): «Capital exógeno y procesos de innovación en la industria vinícolas de la denominación de origen Toro», Boletín de la Asociación de Geógrafos Españoles, no 36, pp. 61-80.

PARENTEAU, A. (2010): «Estado del turismo enológico en Europa». Libro de actas del $2^{\circ}$ Congreso Europeo de Turismo industrial, Toledo 2008, pp. 166-170.

PIQUERAS, J. (2005): «La filoxera en España y su difusión espacial: 1878-1926», Cuadernos de Geografía, no 77 , pp. 101-136.

PIQUERAS, J. (2009): «La vid y el vino en Alacant: una síntesis histórica», en La vid y el vino en Alicante, Revista del Instituto Alicantino de Cultura Juan Gil-Albert, Alicante, pp. 11-26.

PULIDO, J.I. y OTROS (2011): «El turismo rural en España. Orientaciones estratégicas para una tipología aún en desarrollo», Boletín de la Asociación de Geógrafos Espanoles, $\mathrm{n}^{\circ} 56,155-176$.

RICO, A. (2006): «Políticas agrarias, eficiencia socioeconómica y retos de futuro en los regadíos intensivos», Boletín de la Asociación de Geógrafos Españoles, n 41, pp. 113-150.

SILVA, R. (2002): «Estrategias de inserción de las áreas rurales en la economía mundial. Una aproximación desde Andalucía», Boletín de la Asociación de Geógrafos Españoles, $\mathrm{n}^{\mathrm{o}} 33$, pp. 103-134.

UNWIN, T. (1991): Wine and Vine: An Historical Geography, London, Routledge.

VELASCO, M. (2009): «Gestión turística del patrimonio cultural: enfoques para un desarrollo sostenible del turismo cultural», Cuadernos de Turismo, n 23, pp. 237-235.

WARDE, A. (1997): Consumption, Food and Taste, Sage, London.

ZARATE, M.A. (2010): La «visita de empresa» en España, una modalidad turística en expansión. Libro de actas del $2^{\circ}$ Congreso Europeo de Turismo industrial, Toledo 2008, pp. 52-66. 


\section{WEBGRAFÍA}

www.regmurcia.com

www.wineoutesofspain.com/

www.jumilla.org/turismo/RutaVino.asp

www.elecodejumilla.es

www.rutadelvinoyecla.com

www.yecla.como/ayuntamiento/

https://twitter.com/RutaVinoYecla

www.crdo-alicante.org/

http://www.rutadelvinodealicante.com/web/index.html

www.megalvinos.com/

www.apoloybaco.com/DOAlicante.htm

\section{ANEXO (ENTREVISTA PARA EL ANÁLISIS DAFO)}

\section{ANEXO I}

Listado de preguntas realizadas en las entrevistas a personas relevantes en aspectos relacionados con el enoturismo en las comarcas del Vinalopó (Alicante) y Altiplano (Murcia)

$1^{\circ}$ ¿Cuál es a su juicio, la valoración global de la calidad turística de la Ruta del Vino de su ciudad?. Trate de calificarla como «muy buena, buena, aceptable, regular, mala»

$2^{\circ}$ En relación a la pregunta anterior: cuando ha emitido tal valoración. ¿En qué aspectos concretos ha pensado o tenido en cuenta?

$3^{\circ}$ ¿Cuáles son los aspectos más necesitados de una mejora urgente? ¿Cuáles serían dentro de estos aspectos lo más difíciles para poner en funcionamiento? Le rogamos justifique su respuesta.

$4^{\circ}$ A continuación le pedimos lleve a cabo un análisis D.A.F.O. sobre la Gestión e Imagen que tiene la «Ruta del Vino en su ciudad» según su criterio personal. Señale en forma de frases cortas los siguientes aspectos:

\begin{tabular}{|c|c|}
\hline DEBILIDADES & FORTALEZAS \\
\hline & \\
\hline AMENAZAS & OPORTUNIDADES \\
\hline & \\
\hline & \\
\hline
\end{tabular}

$5^{\circ}$ Finalmente, le pedimos realice algún comentario que entienda no se le haya formulado para la valoración actual y mejora de la Ruta del Vino y actividades enoturistas de la comarca del Vinalopó/Altiplano. 
